\title{
Cost Effectiveness of Pharmacological Management for Osteoarthritis: A Systematic Review
}

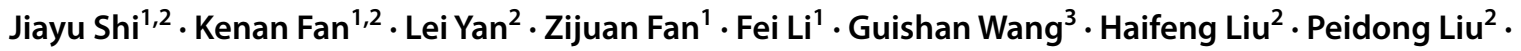 \\ Hongmei $\mathrm{Yu}^{1} \cdot$ Jiao Jiao $\mathrm{Li}^{4} \cdot$ Bin Wang ${ }^{2,5}$
}

Accepted: 16 January 2022 / Published online: 9 February 2022

(c) The Author(s) 2022

\begin{abstract}
Background and objective Osteoarthritis (OA) is a highly prevalent, disabling disease requiring chronic management that is associated with an enormous individual and societal burden. This systematic review provides a global cost-effectiveness evaluation of pharmacological therapy for the management of OA.

Methods Following Center for Reviews and Dissemination (CRD) guidance, a literature search strategy was undertaken using PubMed, EMBASE, Cochrane Library, Health Technology Assessment (HTA) database, and National Health Service Economic Evaluation database (NHS EED) to identify original articles containing cost-effectiveness evaluation of OA pharmacological treatment published before 4 November 2021. Risk of bias was assessed by two independent reviewers using the Joanna Briggs Institute (JBI) critical appraisal checklist for economic evaluations. The Quality of Health Economic Studies (QHES) instrument was used to assess the reporting quality of included articles.

Results Database searches identified 43 cost-effectiveness analysis studies (CEAs) on pharmacological management of OA that were conducted in 18 countries and four continents, with one study containing multiple continents. A total of four classes of drugs were assessed, including non-steroidal anti-inflammatory drugs (NSAIDs), opioid analgesics, symptomatic slowacting drugs for osteoarthritis (SYSADOAs), and intra-articular (IA) injections. The methodological approaches of these studies showed substantial heterogeneity. The incremental cost-effectiveness ratios (ICERs) per quality-adjusted life-year (QALY) were (in 2021 US dollars) US $\$ 44.40$ to US $\$ 307,013.56$ for NSAIDS, US $\$ 11,984.84$ to US $\$ 128,028.74$ for opioids, US $\$ 10,930.17$ to US $\$ 27,799.73$ for SYSADOAs, and US $\$ 258.36$ to US $\$ 58,447.97$ for IA injections in different continents. The key drivers of cost effectiveness included medical resources, productivity, relative risks, and selected comparators.

Conclusion This review showed substantial heterogeneity among studies, ranging from a finding of dominance to very high ICERs, but most studies found interventions to be cost effective based on specific ICER thresholds. Important challenges in the analysis were related to the standardization and methodological quality of studies, as well as the presentation of results.
\end{abstract}

\section{Introduction}

Osteoarthritis (OA) is a highly prevalent musculoskeletal disorder that is associated with a significant health and economic burden. Worldwide, OA affected more than 303 million people in 2017 [1]. It has become an increasing global health concern due to the aging population and the frequent occurrence of multiple co-morbidities, such

Jiayu Shi and Kenan Fan contributed equally.

Jiao Jiao Li

jiaojiao.li@uts.edu.au

$\triangle$ Bin Wang

wangbin_pku@163.com

Extended author information available on the last page of the article

\section{Key Points for Decision Makers}

Economic evaluations have expanded to advanced models such as Markova and the Osteoarthritis Policy models that incorporate considerations for longer time ranges, health utility, a wider range of adverse events including cardiovascular events, and additional meaningful outcomes such as the cost per QALY ICERs.

Differences in study design and between health systems of different countries hampered meaningful comparison of results across studies.

The key drivers of cost effectiveness included medical resources, productivity, relative risks, and selected comparators. 
as cardiovascular disease and diabetes mellitus, in $\mathrm{OA}$ patients. The pain and disability imposed by OA create significant negative impacts on the patient's quality of life, and are important clinical considerations in chronic disease management [2]. OA can affect any joint, but most commonly the knee, hands and hip [3, 4]. OA is comparable to diabetes in disability burden, with both responsible for the largest increases in years lived with disability (YLD) at the global population level compared with the other top 20 causes of disability in 1990-2005 and 2005-2015 [5, 6]. OA accounted for $3.9 \%$ of YLD in 2015, and by 2020 it is expected to be the fourth leading cause of YLD globally $[7,8]$. In addition to imposing a huge disability burden, the direct and indirect costs of OA are continually increasing, which bring a series of socioeconomic consequences: increased expenditure, reduced productivity, over-utilization of healthcare resources, and an overall decline in quality of life for both patients and caretakers [2,9]. In addition, due to their age and likely presence of co-morbidities, OA patients have higher risks of experiencing complications than the general population $[10,11]$. Pharmacological therapy is associated with a range of adverse events (AEs) in OA patients, leading to an increase in direct costs and adding to the already significant economic burden on patients and healthcare systems [12].

Common pharmacological therapies for OA include non-steroidal anti-inflammatory drugs (NSAIDs), opioid analgesics, symptomatic slow-acting drugs for osteoarthritis (SYSADOAs), and intra-articular (IA) injections of substances such as corticosteroids and hyaluronic acid [13] (Fig. 1). According to the recommended treatment modalities for OA by Osteoarthritis Research Society International (OARSI) [14, 15], When choosing pharmaceuticals for the management of OA patients, it is important to consider the risk of complications. For instance, topical NSAIDs were strongly recommended for individuals with knee OA (Level 1A recommendation: $\geq 75 \%$ in favor and $>50 \%$ strong recommendation). For individuals with gastrointestinal co-morbidities, COX-2 inhibitors had a Level 1B recommendation and NSAIDs with proton pump inhibitors had a Level 2 recommendation, while for individuals with cardiovascular comorbidities or frailty, oral NSAIDs were not recommended. Clinical decision making for the pharmacological management of OA should be specific to individual patient conditions. To enable this, physicians should be well informed of the treatment options available, including their relative risks, accessibility, and cost effectiveness.

Health economic evaluations have become increasingly important to support the setting of priorities in healthcare, and to help decision makers allocate healthcare resources efficiently [16]. This is a critical but under-reported aspect in OA management, particularly given the heavy economic burden of OA disability that is likely to worsen due to ongoing population aging, and limited healthcare resources for long-term OA treatment especially in rural or marginalized communities. Most results of economic evaluations are presented using the incremental cost-effectiveness ratio (ICER) [17]. The ICER relates the difference in cost between a medicine and its comparator to the difference in outcomes, and is needed for resource allocation policy making. If the new treatment is less expensive and more clinically effective than the standard treatment, it is said to be dominant. However, if the new treatment is more expensive but also more clinically effective, the new treatment is said to be cost effective if the ICER is less than the willingness to pay (WTP) for each individual country. ICERs can be presented as the cost per quality-adjusted life-year (QALY) gained, where one QALY equates to one year in perfect health.

An overview of existing studies analyzing the cost effectiveness of pharmacological interventions for OA would be useful for identifying the gaps in the current evidence, guiding researchers in designing and conducting high-quality economic evaluations, and helping administrators make decisions based on high-quality evidence. In the absence of a current review on this topic, and in light of previous reviews published in related areas [18-25], the purpose of this study is to systematically review economic evaluations for the pharmacological management of OA.

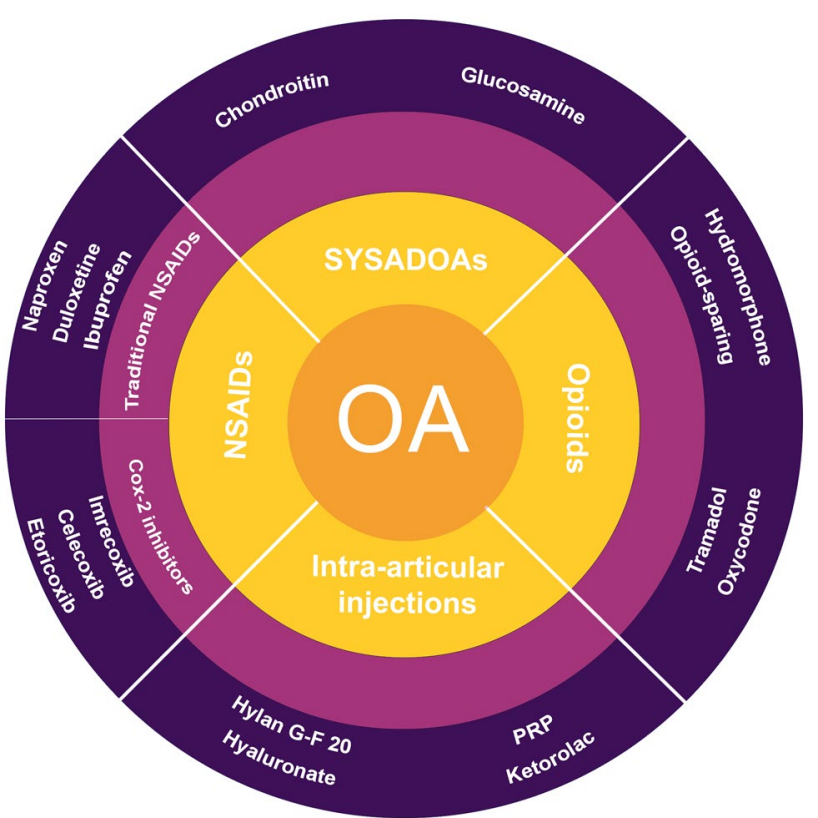

Fig. 1 Classification and types of pharmaceuticals used for osteoarthritis treatment 


\section{Methods}

\subsection{Design}

A structured systematic literature search was performed in November 2021, using a review protocol based on established standards (Center for Reviews and Dissemination guidelines) and integrated with prior methods [26, 27]. This review protocol aimed to limit bias and ensure the best objectivity of the systematic review (Appendix 1, see electronic supplementary material [ESM]).

\subsection{Search Strategy}

Published literature from inception to November 2021 reporting the cost effectiveness of pharmacological management of OA was identified by searching the following databases: PubMed, EMBASE, Cochrane Library, the Health Technology Assessment (HTA) database, and the National Health Service Economic Evaluation database (NHS EED) (this database ceased to be updated after March 2015). 'Osteoarthritis' and 'economic evaluation' and free vocabulary terms were used as MeSH/Emtree search terms. Regular alerts were established to update the search until 4 November 2021. In addition, the reference lists of relevant systematic reviews and meta-analyses were scanned to identify potentially eligible studies. The detailed search strategies are presented as supplementary materials (Appendix 2, see ESM). All searches were supplemented by reviewing the bibliography of publications included for full-text review to identify any additional eligible studies.

\subsection{Study Selection}

Searches were downloaded from each of the databases and uploaded into Endnote X9 for document management. First, duplicates were identified and removed. Second, two reviewers (KNF, ZJF) independently applied inclusion and exclusion criteria (Table 1) to screen titles and abstracts of the remaining articles. Third, the full texts of eligible articles were screened in-depth by two independent reviewers (KNF and ZJF). Any studies resulting in disagreement between the reviewers were presented to a third reviewer (LY) for review and consensus. Subsequently, full-text articles were used for data extraction into an Excel spreadsheet and reviewed by the first author (JYS). Finally, reference lists and citations of eligible articles were checked manually for any additional relevant studies.

\subsection{Data Extraction}

A standardized data-extraction form was developed to collect data from eligible studies. Study characteristics regarding publication (author, year of publication), study design (country/region, perspective, model type, outcome measure, time horizon, comparators, cost type, discount rates, year of valuation), and study results (costs, effectiveness, base-case ICERs, and sensitivity analysis [SA]) were extracted by two reviewer (ZJF, KNF) and checked by a third reviewer (JYS). Afterwards, for comparability reasons, all extracted costs and ICERs were converted into 2021 US dollars using the yearly inflation rates of the countries involved (http://www. rateinflation.com) and the exchange rate published by the Bank of America (https://www.bankofamerica.com/foreignexchange/exchange-rates.go).

\subsection{Assessment for Risk of Bias}

Eligible studies were critically appraised by two independent reviewers (JYS, ZJF) at the study level for methodological quality using the standardized critical appraisal instrument for economic evaluations in the Joanna Briggs Institute

Table 1 Eligibility criteria

\begin{tabular}{|c|c|c|}
\hline Category & Inclusion criteria & Exclusion criteria \\
\hline Population & A population including OA patients & \\
\hline Intervention & $\begin{array}{l}\text { Any pharmacological intervention given for the treatment of } \\
\text { OA }\end{array}$ & COX2 inhibitors removed from the market (e.g. rofecoxib) \\
\hline Comparators & $\begin{array}{l}\text { Any other strategy, including other pharmacological interven- } \\
\text { tion, usual care, or 'doing nothing' }\end{array}$ & \\
\hline Study design & $\begin{array}{l}\text { Full health economic evaluations (CEAs) defined by the pres- } \\
\text { entation of at least one incremental cost-effectiveness ratio } \\
\text { (ICER) or that found an intervention to be dominant }\end{array}$ & $\begin{array}{l}\text { Partial health economic evaluations (e.g., cost minimization } \\
\text { and cost consequence studies were excluded if they did } \\
\text { not also include an ICER outcome); case studies; com- } \\
\text { mentaries; editorials; letters; conference abstracts; research } \\
\text { protocols; animal studies }\end{array}$ \\
\hline Language & English & \\
\hline Publication date & Published before 3 November 2021 & \\
\hline
\end{tabular}

$O A$ osteoarthritis, CEA cost-effectiveness analysis, ICER incremental cost-effectiveness ratio 
(JBI) System for the Unified Management, Assessment and Review of Information [28-30]. All studies, regardless of their methodological quality, underwent data extraction and synthesis. There was no disagreement among the reviewers during the methodological quality assessment. We determined the level of methodological quality as follows: poor quality $=<40 \%$ of the items presented; moderate quality $=$ $41 \%-80 \%$ of the items presented; good quality $=>80 \%$ of the items presented.

\subsection{Assessment for Quality of Reporting}

We graded the included studies by using the Quality of Health Economic Studies (QHES) instrument that assesses studies for the appropriateness of their methods, the validity and transparency of their results, and the comprehensiveness of how they are reported [31]. The QHES is a 16-item scale that uses a dichotomous 'yes' or 'no' response for each item. A 'yes' is worth a specific number of points for each item (reflecting its relative importance), and a 'no' is worth zero. For each study, the points are summed to get a total score that can range from $0=$ 'extremely poor' quality to $100=$ 'excellent' quality. The QHES has demonstrated good overall construct validity $[31,32]$. Based on the total score threshold recommended by Ofman et al. [24], the included studies were classified as either 'high' ( $\geq 75$ points) or 'low' ( $<75$ points) quality. Because instruments for assessing the quality of cost-effectiveness analyses have, in general, been found to have poor inter-rater reliability [33], we established a protocol for using the QHES specifically for this review on the basis of Pinto et al. [20] (Appendix 3, see ESM). Two authors (JYS and ZJF) independently assessed the studies by using these guidelines, with final scoring based on consensus; if a consensus could not be reached, a third author (KNF) mediated.

\subsection{Data Synthesis}

Data extracted from included studies were analyzed and summarized using narrative and tables.

\section{Results}

\subsection{Study Selection and Assessment}

The study selection process is presented in Fig. 2. The literature search resulted in 6106 potential articles, of which 43 CEAs on the pharmacological management of OA were included for analysis. The included studies were conducted in 18 countries on four continents, with one study containing data from multiple continents. The categories and types of pharmaceuticals used for OA treatment are presented in
Fig. 1. The overall methodological quality of the included studies was moderate (Appendix 4, see ESM). The quality of most of the included studies assessed by QHES was high (mean QHES score 84). Six studies [34-39] missed the 75-point threshold demarcating 'low-quality' studies from 'high-quality' ones (Appendix 5, see ESM).

\subsection{Characteristics of Included Studies}

Characteristics of the included studies are reported in Table 2. The time periods of publication were 2000-2004 $(n=6)$ [40-45], 2005-2009 $(n=10)$ [34, 35, 37, 46-52], 2010-2014 $(n=10)$ [53-62], and post-2015 $(n=17)$ [36, 38, 39, 63-76]. The studies were conducted in Europe $(n=15)$, North America $(n=19)[36,37,39,42,45,46,48$, 51, 54-56, 59, 60, 67-72, 75], South America $(n=1)$ [65], and Asia $(n=7)[35,44,62,66,73,74,76]$, and there was also a multi-continental study $(n=1)$ [34]. Study designs included model simulations of OA $(n=33)$ [37-44, 46-50, 53-60, 65-76], randomized clinical trials $(n=8)$ [34-36, 45, $51,52,61,64]$, and observational studies $(n=2)[62,63]$.

Different analysis perspectives were used to evaluate treatment costs for OA pharmaceuticals. The payer perspective was typically adopted, including third-party payer, private payer, National Health Service (NHS), and Healthcare System (HCS). The majority of articles adopted NHS $(n=8)$ [38, 43, 49, 50, 53, 57, 58, 74], third-party payer $(n=3)[55,56,65]$, or HCS perspectives $(n=7)[38,48$, $58,70]$. A number of CEAs offered societal perspectives $(n=8)$ [35, 37, 41, 44, 46, 54, 60, 69]. However, just one such CEA included direct costs and productivity loss [44]. Four offered both NHS and societal perspectives [45, 51, $52,64]$ and others adopted various perspectives, while one article did not report a perspective [36].

The treatment selected as the intervention varied across the studies included in this review. Most studies used NSAIDs and/or coxibs as interventions, which were often combined with a proton pump inhibitor (PPI). A total of 13 studies used IA injection as the intervention [36, 39, 45, 59, $68,71,72]$, while three studies used opioids only [34, 49, 61]. Economic evaluation typically compares an intervention with current best practice or usual care, which may vary by clinical setting. The results from the seven articles that defined the comparator as appropriate care [45], usual care (UC) [64, 75], current care [49], standard care [67], and conventional care $[59,68]$ might not be transferrable because the details of these treatments were unclear.

Numerous sets of cost-effectiveness outcomes were evaluated in the included studies. In addition to cost per minimal perceptible clinical improvement (MPCI) [42], cost per patient improved $[45,51]$, and cost per life-year gained [40, 41], a variety of gastrointestinal (GI)-related outcomes were used, such as cost per GI event avoided [42], and cost 


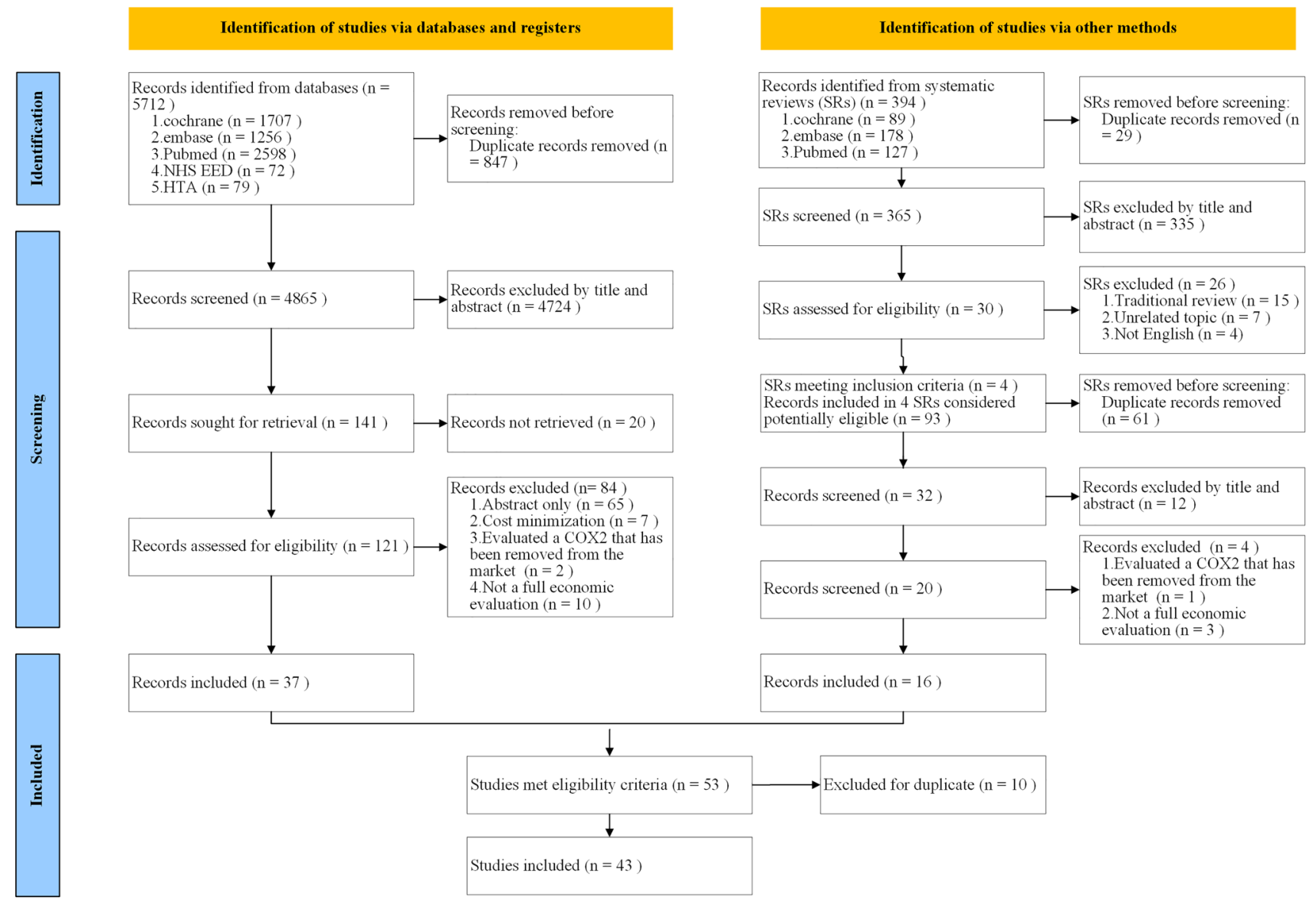

Fig. 2 PRISMA diagram showing the study selection process

per perforation, ulcer or bleed avoided [43]. The use of these variable outcome measures was due to the sources of GI adverse event data included in these studies. The remaining studies reported cost-utility analyses with QALY as the outcome measure. To estimate health utilities for a QALY calculation, the Western Ontario McMaster University Osteoarthritis Index (WOMAC) [77] or another instrument (Sleep Problems Index [SPI]) were often translated into a utilitybased instrument (e.g. the EQ-5D or Health Utility Index [HUI]). Four studies $[34,49,61,68]$ translate WOMAC into the HUI and three $[50,53,66]$ into EQ-5D, while five studies $[52,56,62-64]$ directly used the EQ-5D and three [45, 51, 59] use the HUI3.

\subsection{Data Analysis}

\subsubsection{Cost Effectiveness of Drugs Estimates in Asia}

Table 3 identifies seven articles evaluating economic outcomes in Asia [35, 44, 62, 66, 73, 74, 76]. Three evaluations were conducted in the China region $[35,44,76]$, two of which were in Taiwan [35, 44], and one evaluation was conducted in each of the following countries: Japan [74], Saudi Arabia [66], and United Arab Emirates [73]. Most of these economic comparisons were made between coxibs (celecoxib or imrecoxib) and NSAIDs with or without gastroprotection. Differences in study design and between health systems in each country hampered meaningful comparison of results across studies. The authors of these studies concluded that coxibs (celecoxib or imrecoxib) were cost effective in these geographical regions based on the local standards. In these studies, the incremental effectiveness between the treatment and control groups varied between 0.0023 and 1.49 QALYs, and the ICERs varied between US $\$ 44.40$ and US $\$ 58,447.97$ per QALY gained. In addition, the two articles from Taiwan [35, 44] reported that IA injection was performed. One of these concluded that hyaluronic acid therapy might not be an economically attractive option since Taiwan has fewer health resources than other places, such as Canada and the US [44]. Of the seven studies included, one reported a threshold range, three reported a single threshold, and the remaining three studies did not report a threshold. 


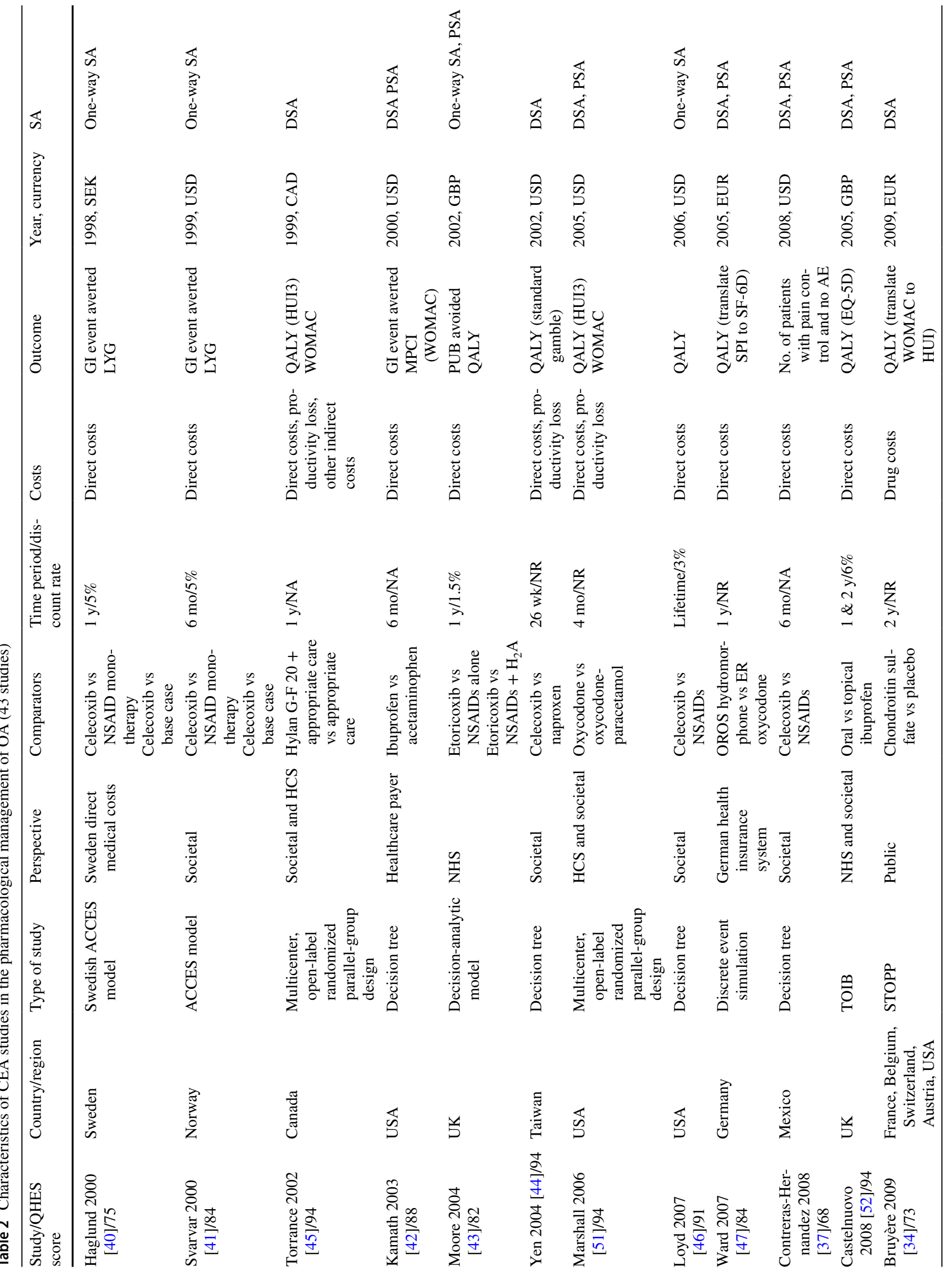




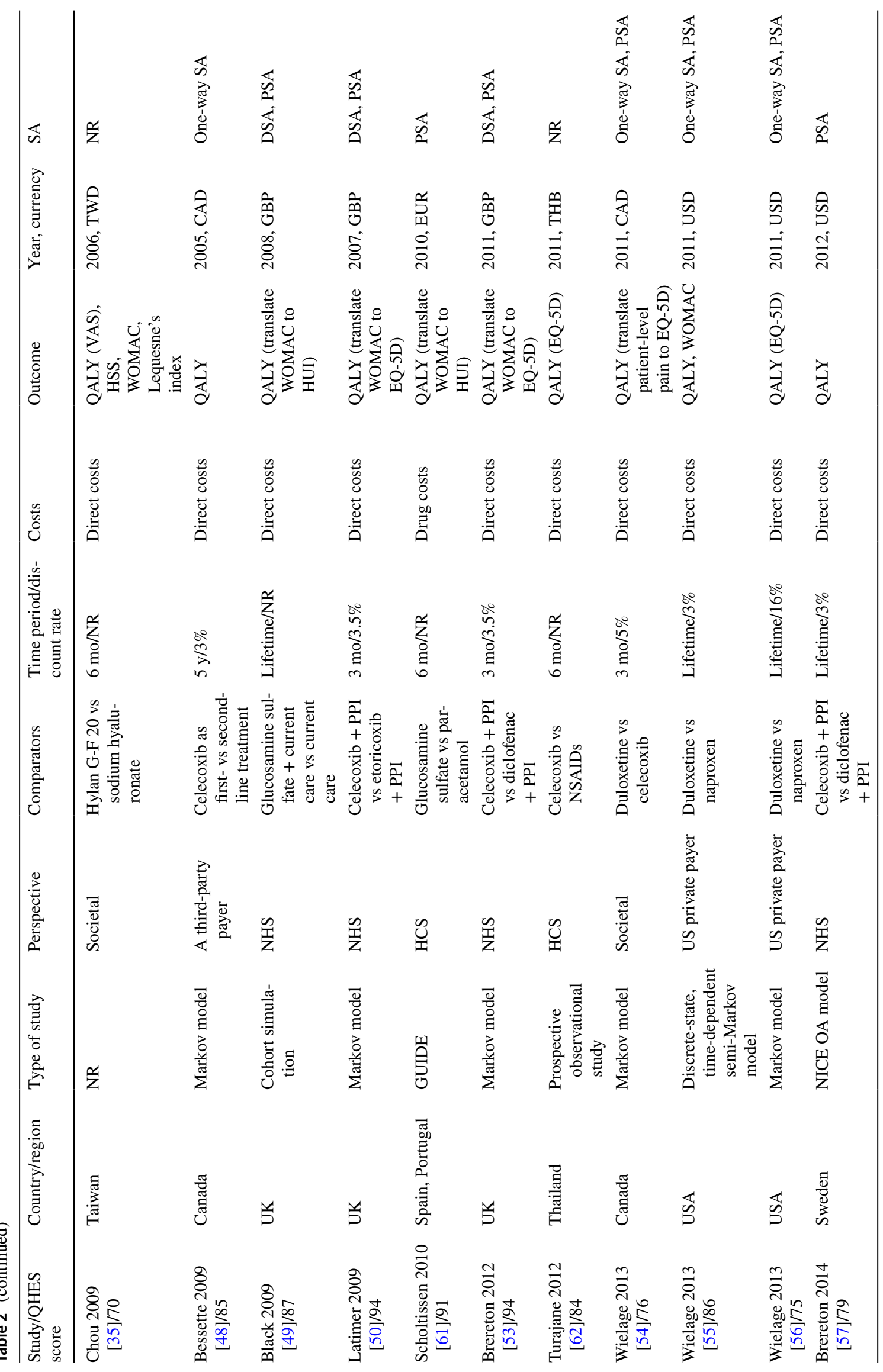




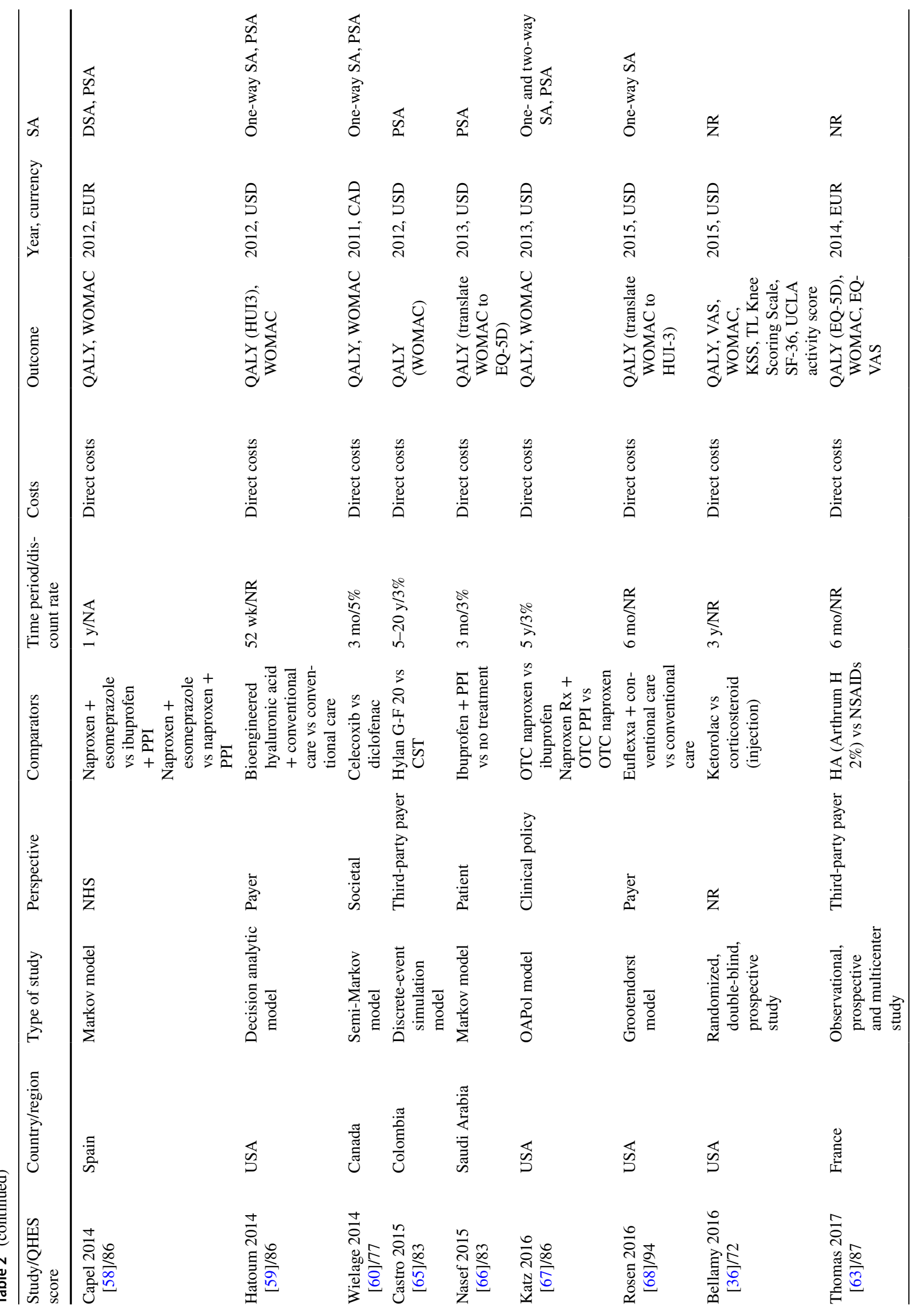




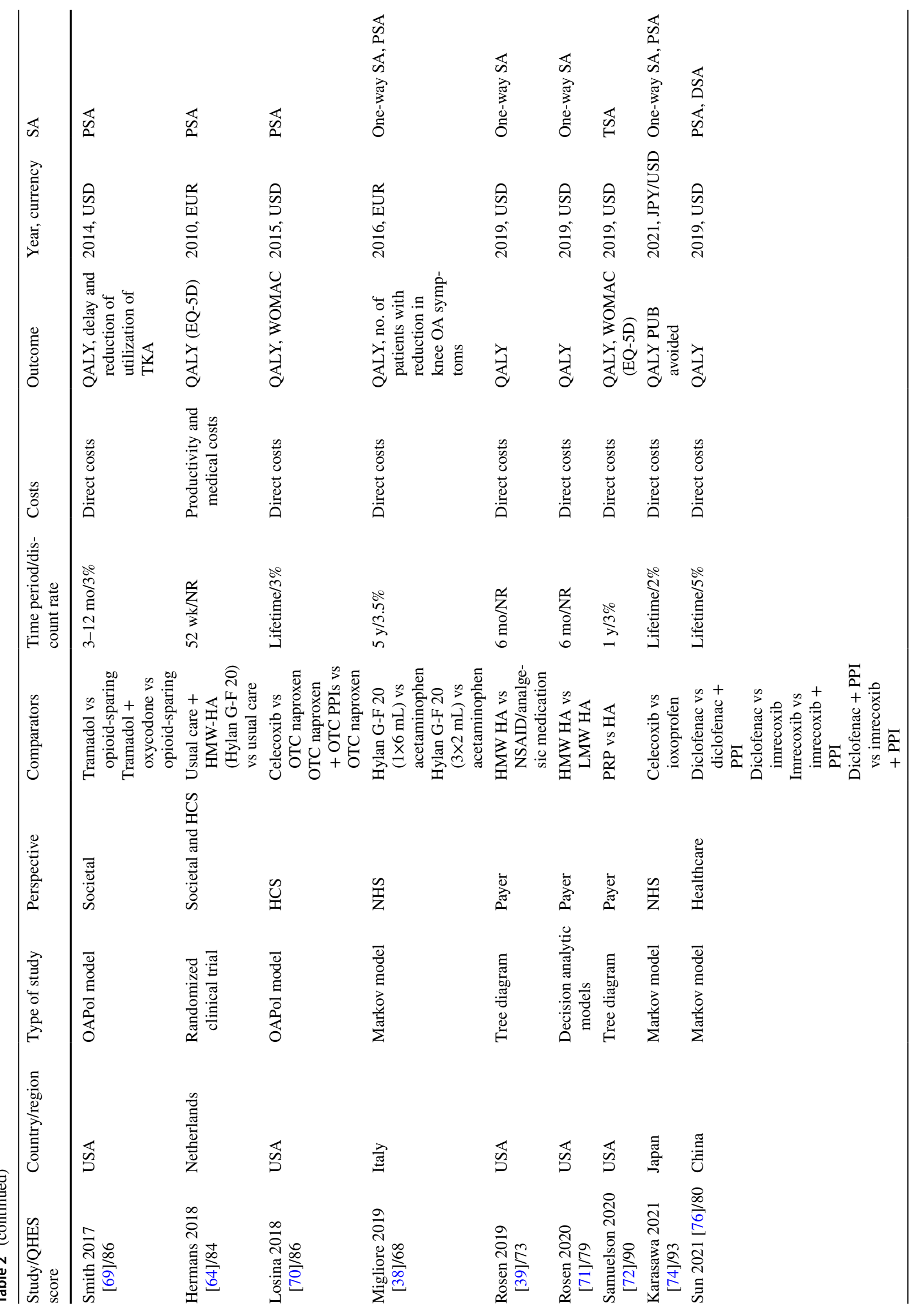




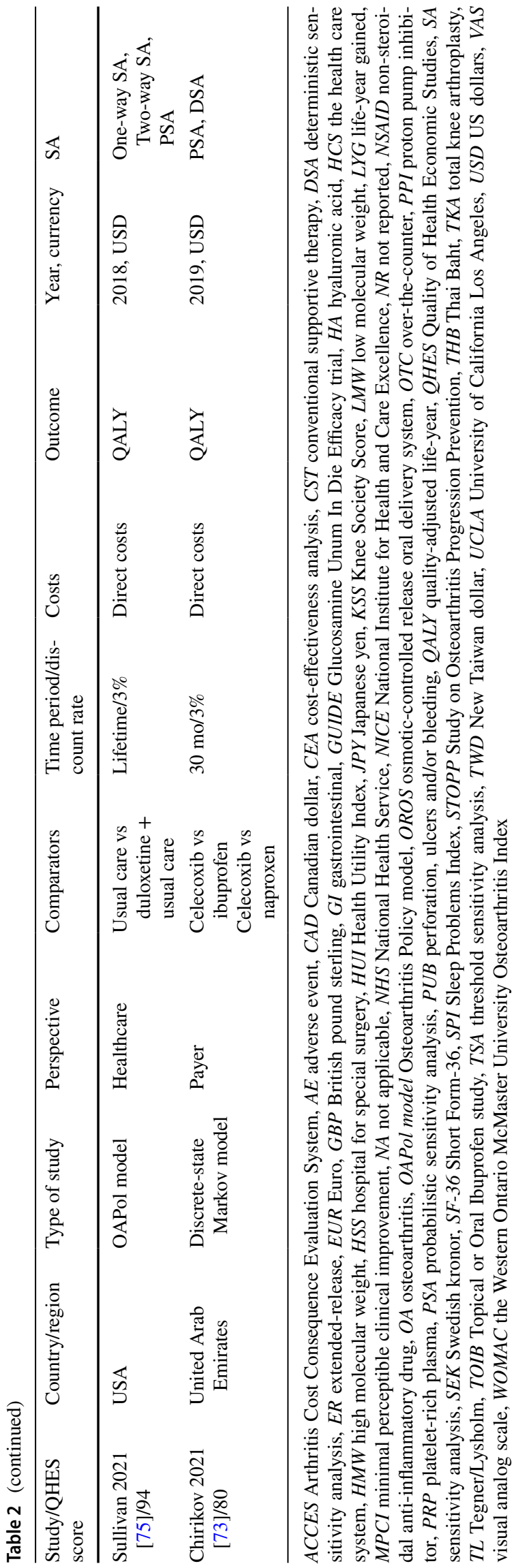

\subsection{Cost Effectiveness of Drugs Estimates in Europe}

Table 4 presents a total of 15 studies conducted in nine European countries, with one study involving two countries [61]. The UK and Sweden were the only countries in which more than one study was conducted. NSAIDs were the most common comparator to celecoxib. Most studies concluded that celecoxib was cost effective compared with other active treatment options based on local standards, and at times dominated comparators (was more effective and less costly) in some countries [37, 40,41]. The cost and incremental effectiveness between the treatment and control groups varied between US\$0.00755 and US\$450.98, and 0.002 and 0.038 QALYs, respectively. The ICERs ranged from US $\$ 6461.63$ to US $\$ 38,686.79$ per QALY gained. Other articles reported IA injections, opioids, and SYSADOAs, and the intervention group showed cost effectiveness compared with the comparators. For IA injections, the cost and incremental effectiveness between the treatment and control groups varied between US $\$ 10.85$ and US $\$ 1647.84$, and 0.042 and 0.35116 QALYs, respectively. The ICERs ranged from US $\$ 258.36$ to US\$10,702.23 per QALY gained. There are three articles reporting a threshold interval and nine reporting a single threshold, while the remaining one did not report a threshold.

\subsection{Cost Effectiveness of Drugs Estimates in the Americas}

Table 5 lists 20 articles assessing the economic evaluations in the Americas, performed in three countries (US, Canada, and Colombia). Similar to other continents, celecoxib was considered cost effective when compared with NSAIDs. The ICERs varied between US $\$ 875.91$ and US $\$ 307,013.56$ per QALY gained. The ICER estimates also varied with the subject's pain and age [75]. However, a study comparing celecoxib with over-the-counter (OTC) naproxen showed that celecoxib was not cost effective because of its exorbitant annual price of US\$880 [70]. In addition, one study comparing opioid-based strategies showed that celecoxib was not cost effective because it diminishes the effectiveness of total knee arthroplasty (TKA) [69].

\subsection{Cost Effectiveness of Drugs Estimates Across Continents}

Table 6 lists one article assessing the economic evaluations across continents, performed in five countries (France, Belgium, Austria, Switzerland, and USA). The ICER estimates also varied with the time period. 
Table 3 Cost-effectiveness estimates in Asia (7 studies)

\begin{tabular}{|c|c|c|c|c|c|c|c|}
\hline References & Country/region & $\begin{array}{l}\text { Intervention and } \\
\text { comparator }\end{array}$ & $\Delta$ Cost (US\$) & $\begin{array}{l}\Delta \text { Effec- } \\
\text { tiveness } \\
\text { (QALY) }\end{array}$ & ICER (US\$) & $\begin{array}{l}\text { Cost-effectiveness } \\
\text { threshold (US\$) }\end{array}$ & $\begin{array}{l}\text { Intervention } \\
\text { cost effec- } \\
\text { tive? } \\
(+/-)\end{array}$ \\
\hline \multicolumn{8}{|c|}{ Traditional NSAIDs and/or coxibs } \\
\hline Turajane 2012 [62] & Thailand & $\begin{array}{l}\text { Celecoxib vs } \\
\text { NSAID }\end{array}$ & $\$ 0.84$ & 0.019 & \$44.4/QALY & NR & + \\
\hline \multirow[t]{2}{*}{ Nasef 2015 [66] } & Saudi Arabia & $\begin{array}{l}\text { Celecoxib + PPI vs } \\
\text { ibuprofen + PPI }\end{array}$ & $\$ 120.32$ & 0.06 & $\$ 1980.88$ & \$2255/QALY & + \\
\hline & & $\begin{array}{l}\text { Ibuprofen + PPI vs } \\
\text { no treatment }\end{array}$ & $\$ 1460.39$ & 0.34 & $\$ 4242.90$ & \$2255/QALY & + \\
\hline $\begin{array}{l}\text { Karasawa } 2021 \\
\text { [74] }\end{array}$ & Japan & $\begin{array}{l}\text { Celecoxib vs loxo- } \\
\text { profen }\end{array}$ & $\$ 62.02$ & 0.024 & $\$ 53,466.92$ & NR & + \\
\hline \multirow[t]{2}{*}{ Sun 2021 [76] } & China & $\begin{array}{l}\text { Imrecoxib vs } \\
\text { diclofenac (lower } \\
\text { risk of GI and CV } \\
\text { events) }\end{array}$ & $\$ 614.22$ & 1.49 & $\$ 413.90$ & $\$ 30,921 / \mathrm{QALY}$ & + \\
\hline & & $\begin{array}{l}\text { Imrecoxib vs } \\
\text { diclofenac } \\
\text { (higher risk of GI } \\
\text { and CV events) }\end{array}$ & $\$ 571.06$ & 1.13 & $\$ 507.89$ & $\$ 30,921 / \mathrm{QALY}$ & + \\
\hline \multirow[t]{2}{*}{ Chirikov 2021 [73] } & $\begin{array}{l}\text { United Arab Emir- } \\
\text { ates }\end{array}$ & $\begin{array}{l}\text { Celecoxib vs ibu- } \\
\text { profen }\end{array}$ & $\$ 38.77$ & 0.0032 & $\$ 11,854.92$ & $\begin{array}{l}\$ 41,227-\$ 123,682 / \\
\text { QALY }\end{array}$ & + \\
\hline & & $\begin{array}{l}\text { Celecoxib vs nap- } \\
\text { roxen }\end{array}$ & $\$ 84.22$ & 0.002 & $\$ 40,999.56$ & $\begin{array}{l}\text { \$41,227-\$123,682/ } \\
\text { QALY }\end{array}$ & + \\
\hline \multicolumn{8}{|l|}{ IA injections } \\
\hline Yen 2004 [44] & Taiwan & $\begin{array}{l}\text { Celecoxib vs nap- } \\
\text { roxen }\end{array}$ & $\$ 67.94$ & 0.0023 & $\$ 29,178.43$ & $\begin{array}{l}2002 \text { Taiwan } \\
\text { GDP per } \\
\text { capita }(\$ 18,399) \\
\$ 46,773 / \mathrm{QALY}\end{array}$ & + \\
\hline Yen 2004 [44] & Taiwan & $\begin{array}{l}\text { Hyaluronan vs } \\
\text { celecoxib }\end{array}$ & $\$ 181.19$ & 0.0031 & $\$ 58,447.97$ & $\begin{array}{l}2002 \text { Taiwan } \\
\text { GDP per } \\
\text { capita }(\$ 18,399) \\
\$ 46,773 / \text { QALY }\end{array}$ & - \\
\hline Chou 2009 [35] & Taiwan & $\begin{array}{l}\text { Hylan G-F } 20 \text { vs } \\
\text { sodium hyaluro- } \\
\text { nate }\end{array}$ & $\$ 51.27$ & 0.019 & Dominant & NR & + \\
\hline
\end{tabular}

$C V$ cardiovascular disease, GI gastrointestinal, IA intra-articular, ICER incremental cost-effectiveness ratio, NR not reported, NSAID non-steroidal anti-inflammatory drug, $P P I$ proton pump inhibitor, $Q A L Y$ quality-adjusted life-year

\subsection{Subgroup Analyses}

Subgroup analyses were conducted by type of study (trialbased or model-based), and time period ( $\leq 1$ year, $1-5$ years, lifetime). The results are presented as tables in the supplementary materials (Appendix 6, see ESM).

\section{Discussion}

In this study, we have addressed gaps (differences in study design and between health systems in each country) in the current evidence by separating the analysis of the cost effectiveness of OA drugs into different continents, and providing up-to-date analyses that would be useful for healthcare providers and payers, as well as researchers for conducting high-quality economic evaluations in the future.

OA is a chronic condition characterized by a long course of disease progression, often associated with severe impacts on the patient's quality of life and risk of mortality from other co-morbidities [78, 79]. The OA disease burden is growing faster than any other health condition globally [5, 80]. Improving patient quality of life and joint function are the primary goals of OA management strategies, for which the choice of appropriate healthcare interventions is critical in the light of rising costs for the OA patient population. Health economic evaluations provide a critical piece of the 
Table 4 Cost-effectiveness estimates in Europe (15 studies)

\begin{tabular}{|c|c|c|c|c|c|c|c|}
\hline Study & Country/region & $\begin{array}{l}\text { Intervention and } \\
\text { comparator }\end{array}$ & $\Delta$ Cost (US\$) & $\begin{array}{l}\Delta \text { Effec- } \\
\text { tiveness } \\
\text { (QALY) }\end{array}$ & ICER (US\$) & $\begin{array}{l}\text { Cost-effectiveness } \\
\text { threshold (US\$) }\end{array}$ & $\begin{array}{l}\text { Intervention cost } \\
\text { effective? (+/-) }\end{array}$ \\
\hline \multicolumn{8}{|c|}{ Traditional NSAIDs and/or coxibs } \\
\hline Haglund $2000[40]$ & Sweden & $\begin{array}{l}\text { Celecoxib vs } \\
\text { NSAID mono- } \\
\text { therapy }\end{array}$ & NR & NR & Dominant & NR & + \\
\hline Svarvar2000 [41] & Norway & $\begin{array}{l}\text { Celecoxib vs } \\
\text { NSAID mono- } \\
\text { therapy }\end{array}$ & NR & NR & Dominant & NR & + \\
\hline $\begin{array}{l}\text { Contreras } 2008 \\
\text { [37] }\end{array}$ & Mexico & $\begin{array}{l}\text { Celecoxib vs } \\
\text { NSAIDs }\end{array}$ & $-\$ 0.00755$ & 0.0097 & Dominant & $\begin{array}{l}\text { Cost-effectiveness } \\
\text { acceptability } \\
\text { curves }\end{array}$ & + \\
\hline Latimer 2009 [50] & UK & $\begin{array}{l}\text { Celecoxib + PPI } \\
\text { vs etoricoxib }+ \\
\text { PPI }\end{array}$ & $\$ 36.28$ & 0.002 & $\$ 18,343.27$ & $\$ 35,243 / \mathrm{QALY}$ & + \\
\hline Brereton 2012 [53] & UK & $\begin{array}{l}\text { Celecoxib + PPI } \\
\text { vs diclofenac }+ \\
\text { PPI }\end{array}$ & $\$ 84.40$ & 0.006 & $\$ 14,131.82$ & $\$ 31,498 / \mathrm{QALY}$ & + \\
\hline Brereton 2014 [57] & Sweden & $\begin{array}{r}\text { Celecoxib+ PPI vs } \\
\text { diclofenac + PPI }\end{array}$ & $\$ 87.93$ & 0.006 & $\$ 13,519.23$ & $\begin{array}{l}\text { 100,000 SEK } \\
(\$ 16,971 / \mathrm{QALY})\end{array}$ & + \\
\hline \multirow[t]{2}{*}{$\begin{array}{l}\text { Castelnuovo } 2008 \\
\text { [52] }\end{array}$} & UK & $\begin{array}{l}\text { Oral vs topical } \\
\text { ibuprofen (SP) }\end{array}$ & $\$ 120.32$ & 0.038 & $\$ 21,588.60$ & $\begin{array}{l}\$ 16,548- \\
\$ 22,065 / \mathrm{QALY}\end{array}$ & + \\
\hline & & $\begin{array}{l}\text { Oral vs topical } \\
\text { ibuprofen (HP) }\end{array}$ & $\$ 450.98$ & 0.038 & $\$ 38,686.79$ & $\begin{array}{l}\$ 16,548- \\
\$ 22,065 / \mathrm{QALY}\end{array}$ & + \\
\hline \multirow[t]{2}{*}{ Moore 2004 [43] } & UK & $\begin{array}{l}\text { Etoricoxib vs } \\
\text { NSAIDs alone }\end{array}$ & $\$ 362.12$ & 0.0097 & $\$ 36,998.82$ & $\$ 57,341 / \mathrm{QALY}$ & + \\
\hline & & $\begin{array}{l}\text { Etoricoxib vs } \\
\text { NSAIDs }+\mathrm{H} 2 \mathrm{~A}\end{array}$ & $\$ 169.95$ & 0.0097 & $\$ 17,364.45$ & $\$ 57,341 / \mathrm{QALY}$ & + \\
\hline \multirow[t]{2}{*}{ Capel 2014 [58] } & Spain & $\begin{array}{l}\text { Naproxen+ } \\
\text { esomeprazole vs } \\
\text { ibuprofen+ PPI }\end{array}$ & $\$ 78.73$ & 0.0041 & $\$ 18,824.96$ & $\$ 38,294 / \mathrm{QALY}$ & + \\
\hline & & $\begin{array}{l}\text { Naproxen + } \\
\text { esomeprazole vs } \\
\text { naproxen+ PPI }\end{array}$ & $\$ 44.23$ & 0.0068 & $\$ 6461.63$ & $\$ 38,294 / \mathrm{QALY}$ & + \\
\hline \multicolumn{8}{|l|}{ IA injections } \\
\hline Thomas 2017 [63] & France & $\begin{array}{l}\text { HA (Arthrum H } \\
2 \% \text { ) vs NSAIDs }\end{array}$ & $\$ 10.85$ & 0.042 & $\$ 258.36$ & $\$ 55,549 / \mathrm{QALY}$ & + \\
\hline \multirow[t]{2}{*}{$\begin{array}{l}\text { Hermans } 2018 \\
{[64]}\end{array}$} & Netherlands & $\begin{array}{l}\text { Usual care + } \\
\text { HMW-HA } \\
\text { (Hylan G-F 20) } \\
\text { vs usual care } \\
\text { (SP) }\end{array}$ & $\$ 561.04$ & 0.052 & $\$ 10,702.23$ & \$26,646/QALY & + \\
\hline & & $\begin{array}{l}\text { Usual care + } \\
\text { HMW-HA } \\
\text { (Hylan G-F 20) } \\
\text { vs usual care } \\
\text { (HP) }\end{array}$ & $\$ 538.60$ & 0.052 & $\$ 10,702.23$ & $\$ 26,646 / \mathrm{QALY}$ & + \\
\hline \multirow[t]{2}{*}{ Migliore 2019 [38] } & Italy & $\begin{array}{l}\text { Hylan G-F } 20 \\
(1 \times 6 \mathrm{~mL}) \text { vs } \\
\text { acetaminophen }\end{array}$ & $\$ 1354.25$ & 0.35116 & $\$ 3856.54$ & $\$ 24,462 / \mathrm{QALY}$ & + \\
\hline & & $\begin{array}{l}\text { Hylan G-F } 20 \\
(3 \times 2 \mathrm{~mL}) \mathrm{vs} \\
\text { acetaminophen }\end{array}$ & $\$ 1647.84$ & 0.35116 & $\$ 4692.61$ & $\$ 24,462 / \mathrm{QALY}$ & + \\
\hline \multicolumn{8}{|l|}{ Opioids } \\
\hline Ward 2007 [47] & Germany & $\begin{array}{l}\text { OROS hydromor- } \\
\text { phone vs ER } \\
\text { oxycodone }\end{array}$ & $\$ 174.43$ & 0.017 & $\$ 11,984.84$ & NR & + \\
\hline
\end{tabular}


Table 4 (continued)

\begin{tabular}{|c|c|c|c|c|c|c|c|}
\hline Study & Country/region & $\begin{array}{l}\text { Intervention and } \\
\text { comparator }\end{array}$ & $\Delta$ Cost (US\$) & $\begin{array}{l}\Delta \text { Effec- } \\
\text { tiveness } \\
\text { (QALY) }\end{array}$ & ICER (US\$) & $\begin{array}{l}\text { Cost-effectiveness } \\
\text { threshold (US\$) }\end{array}$ & $\begin{array}{l}\text { Intervention cost } \\
\text { effective? (+/-) }\end{array}$ \\
\hline \multicolumn{8}{|l|}{ SYSADOAs } \\
\hline Black 2009 [49] & UK & $\begin{array}{l}\text { Glucosamine } \\
\text { sulfate + current } \\
\text { care vs current } \\
\text { care }\end{array}$ & NR & NR & $\$ 17,480.64$ & $\$ 51,675 / \mathrm{QALY}$ & + \\
\hline $\begin{array}{l}\text { Scholtissen } 2010 \\
\text { [61] }\end{array}$ & Spain and Portugal & $\begin{array}{l}\text { Glucosamine sul- } \\
\text { fate vs paraceta- } \\
\text { mol }\end{array}$ & $-\$ 12.69$ & 0.01 & Dominant & $\begin{array}{l}\$ 30,643 \\
\$ 46,630 / \mathrm{QALY}\end{array}$ & + \\
\hline
\end{tabular}

$E R$ extended-release, $H A$ hyaluronic acid, $H M W$ high molecular weight, $H P$ healthcare system perspective, $H 2 A$ histamine $\mathrm{H} 2$ receptor antagonist, IA intra-articular, ICER incremental cost-effectiveness ratio, NR not reported, NSAID non-steroidal anti-inflammatory drug, OROS Osmotic-controlled Release Oral delivery System, PPI proton pump inhibitor, $Q A L Y$ quality-adjusted life-year, $S E K$ Swedish kronor, $S P$ social perspective, SYSADOAs symptomatic slow-acting drugs for osteoarthritis

puzzle for informing clinical decision making related to OA interventions.

In this study, we performed a systematic review of the literature on cost-effectiveness analysis of OA pharmacological interventions, and provided insights into the changes seen in the methodology of these economic evaluations over the past two decades. Over the past years, such evaluations are no longer limited to decision trees and short time ranges that considered only gastrointestinal events, but have expanded to advanced models such as Markov [38, 48, 50, 53-56, 58, 60, 66, 73, 74, 76] and Osteoarthritis Policy models $[67,69,70,75]$ that incorporate considerations for longer time ranges, health utility, a wider range of adverse events including cardiovascular events, and more meaningful outcomes such as the cost per QALY ICERs. Depending on the continents, type of drug, the control group, and duration of follow-up, cost-effectiveness analyses for OA pharmacological interventions reported different ranges of ICER estimates.

Despite a significant growth in pharmacoeconomic evaluation studies of OA in recent years, as well as some innovations in trial and model design, the comparability among various studies remains poor due to a lack of standardized research methods and designs. For instance, our analysis indicated that most studies found celecoxib to be economically attractive compared with NSAIDs with or without gastric protective agents. However, due to significant heterogeneity in the methodology and design of the included studies, it is not possible to provide a confident recommendation. Several sources of study heterogeneity should be considered when interpreting the results of our review. First, different perspectives of cost analysis were adopted among the included studies, such as a payer or societal perspective, introducing inconsistencies into the types of resources that should and should not be compared to evaluate the cost effectiveness of pharmacological interventions.
This is complicated by the fact that the effects of OA are multi-dimensional, involving not only individual disability and reduced quality of life, but also major impacts on overall societal productivity. This level of complexity is rarely being addressed in the current design of CEAs. Second, the included studies used a range of different comparators, such as comparing against baseline (standard care or no intervention) or comparing against other pharmacological interventions, which reduces the ability to make accurate comparisons among studies $[81,82]$. Finally, it is important to note that for a chronic condition such as OA, clinical trials or models spanning only a few months (as seen in a major portion of the included studies) are unlikely to provide evidence that is representative of the entire course of disease. These identified challenges have been discussed in more detail elsewhere [83, 84].

Several key drivers of cost effectiveness were identified in our systematic review, which might have contributed to the variations seen in cost and effectiveness measures across continents. These include medical resources, productivity, relative risks, and selected comparators. Variation in medical resources could lead to different cost effectiveness of OA drugs in different geographical regions. Some economically under-developed areas may have less health resources than economically developed areas, and so some measures that achieve certain benefits but cost more may not be supported $[44,70]$. Two trial studies reported that decreased productivity is the most influential parameter to changes in the cost effectiveness of OA drugs [51, 64]. The time lost by patients had a relatively strong effect on the estimated incremental net monetary benefit from a societal perspective.

It has been noted that the main driver of the cost effectiveness of OA drugs is the relative risk of the drugs, which affects the results of the model. The relative risk of the drug drives the absolute risk of the population, which in turn drives the projected cost of side effects and the risk and 
Table 5 Cost-effectiveness estimates in the Americas (20 studies)

\begin{tabular}{|c|c|c|c|c|c|c|c|}
\hline Study & Country/region & $\begin{array}{l}\text { Intervention and } \\
\text { comparator }\end{array}$ & $\Delta$ Cost (US\$) & $\begin{array}{l}\Delta \text { Effec- } \\
\text { tiveness } \\
(\mathrm{QALY})\end{array}$ & ICER (US\$) & $\begin{array}{l}\text { Cost-effectiveness } \\
\text { threshold (US\$) }\end{array}$ & $\begin{array}{l}\text { Intervention cost } \\
\text { effective? (+/-) }\end{array}$ \\
\hline \multicolumn{8}{|c|}{ Traditional NSAIDs and/or coxibs } \\
\hline Loyd 2007 [46] & US & $\begin{array}{l}\text { Celecoxib vs } \\
\text { NSAIDs }\end{array}$ & $\$ 5205.96$ & 0.1304 & $\$ 39,436.80$ & $\$ 79,515 / \mathrm{QALY}$ & + \\
\hline Bessette 2009 [48] & Canada & $\begin{array}{l}\text { Celecoxib as first- } \\
\text { vs second-line } \\
\text { treatment }\end{array}$ & $\$ 1331.45$ & 0.02 & $\$ 51,656.40$ & NR & + \\
\hline Wielage 2014 [60] & Canada & $\begin{array}{l}\text { Celecoxib vs } \\
\text { diclofenac }\end{array}$ & $\$ 53.10$ & 0.0024 & $\$ 23,818.81$ & $\$ 59,345 / \mathrm{QALY}$ & + \\
\hline \multirow[t]{2}{*}{ Losina 2018 [70] } & US & $\begin{array}{l}\text { Celecoxib vs OTC } \\
\text { naproxen }\end{array}$ & $\$ 450.98$ & 0.005 & $\$ 307,013.56$ & $\$ 109,325 / \mathrm{QALY}$ & - \\
\hline & & $\begin{array}{l}\text { OTC naproxen + } \\
\text { OTC PPIs vs OTC } \\
\text { naproxen }\end{array}$ & $\$ 450.98$ & 0.007 & $\$ 63,639.81$ & $\$ 109,325 /$ QALY & - \\
\hline Kamath 2003 [42] & US & $\begin{array}{l}\text { Ibuprofen vs aceta- } \\
\text { minophen }\end{array}$ & $\$ 71.23$ & 0.08 & $\$ 875.91$ & $\begin{array}{l}\text { Cost-effectiveness } \\
\text { acceptability } \\
\text { curves }\end{array}$ & + \\
\hline Wielage 2013 [54] & Canada & $\begin{array}{l}\text { Duloxetine vs } \\
\text { celecoxib }\end{array}$ & $\$ 624.72$ & 0.0169 & $\$ 36,613.26$ & $\$ 59,345 / \mathrm{QALY}$ & + \\
\hline Wielage 2013 [55] & US & $\begin{array}{l}\text { Duloxetine vs } \\
\text { naproxen }\end{array}$ & $\$ 1458.94$ & 0.0266 & $\$ 54,188.77$ & $\$ 59,345 / \mathrm{QALY}$ & + \\
\hline Wielage 2013 [56] & US & $\begin{array}{l}\text { Duloxetine vs } \\
\text { naproxen }\end{array}$ & $\$ 1533.73$ & 0.0266 & $\$ 67,594.46$ & $\$ 59,345 / \mathrm{QALY}$ & + \\
\hline \multirow[t]{2}{*}{ Katz 2016 [67] } & US & $\begin{array}{l}\text { Naproxen OTC vs } \\
\text { ibuprofen }\end{array}$ & $\$ 426.13$ & 0.007 & $\$ 60,139.76$ & $\$ 112,726 / \mathrm{QALY}$ & + \\
\hline & & $\begin{array}{l}\text { Naproxen } \mathrm{Rx}+\text { PPI } \\
\text { OTC vs naproxen } \\
\text { OTC }\end{array}$ & $\$ 2130.31$ & 0.025 & $\$ 84,173.71$ & $\$ 112,726 / \mathrm{QALY}$ & + \\
\hline \multirow[t]{6}{*}{ Sullivan 2021 [75] } & US & $\begin{array}{l}\text { Duloxetine }+ \text { usual } \\
\text { care vs usual care } \\
\text { (57 years old and } \\
\text { WOMAC pain } 55 \text { ) }\end{array}$ & $\$ 950.27$ & 0.009 & $\$ 93,442.99$ & $\$ 93,443 / \mathrm{QALY}$ & + \\
\hline & & $\begin{array}{l}\text { Duloxetine }+ \text { usual } \\
\text { care vs usual care } \\
(65 \text { years old and } \\
\text { WOMAC pain } 55)\end{array}$ & $\$ 844.68$ & 0.005 & $\$ 167,458.29$ & $\$ 93,443 / \mathrm{QALY}$ & + \\
\hline & & $\begin{array}{l}\text { Duloxetine }+ \text { usual } \\
\text { care vs usual care } \\
\text { (75 years old and } \\
\text { WOMAC pain } 55 \text { ) }\end{array}$ & $\$ 739.10$ & 0 & Dominated $^{2}$ & $\$ 93,443 / \mathrm{QALY}$ & + \\
\hline & & $\begin{array}{l}\text { Duloxetine }+ \text { usual } \\
\text { care vs usual care } \\
(57 \text { years old and } \\
\text { WOMAC pain } 25)\end{array}$ & $\$ 1372.61$ & 0.031 & $\$ 45,296.09$ & $\$ 93,443 / \mathrm{QALY}$ & + \\
\hline & & $\begin{array}{l}\text { Duloxetine }+ \text { usual } \\
\text { care vs usual care } \\
(65 \text { years old and } \\
\text { WOMAC pain } 25)\end{array}$ & $\$ 1267.02$ & 0.03 & $\$ 40,755.93$ & $\$ 93,443 / \mathrm{QALY}$ & + \\
\hline & & $\begin{array}{l}\text { Duloxetine }+ \text { usual } \\
\text { care vs usual care } \\
\text { (75 years old and } \\
\text { WOMAC pain } 25 \text { ) }\end{array}$ & $\$ 1161.44$ & 0.03 & $\$ 40,755.93$ & $\$ 93,443 / \mathrm{QALY}$ & + \\
\hline
\end{tabular}

cost of post-event switch in therapy [37], and also reduces quality of life, resulting in an increase in ICER [41, 53, 54, 57]. Some studies have shown that cost effectiveness varies among the selected comparators. The adverse events rate and PPI utilization rate may vary when different comparators are used, which have a great impact on the results of the 
Table 5 (continued)

\begin{tabular}{|c|c|c|c|c|c|c|c|}
\hline Study & Country/region & $\begin{array}{l}\text { Intervention and } \\
\text { comparator }\end{array}$ & $\Delta$ Cost (US\$) & $\begin{array}{l}\Delta \text { Effec- } \\
\text { tiveness } \\
(\text { QALY) }\end{array}$ & ICER (US\$) & $\begin{array}{l}\text { Cost-effectiveness } \\
\text { threshold (US\$) }\end{array}$ & $\begin{array}{l}\text { Intervention cost } \\
\text { effective? (+/-) }\end{array}$ \\
\hline \multicolumn{8}{|l|}{ IA injections } \\
\hline \multirow[t]{2}{*}{ Torrance 2002 [45] } & Canada & $\begin{array}{l}\text { Hylan G-F } 20+ \\
\text { appropriate care } \\
\text { vs appropriate } \\
\text { care (SP) }\end{array}$ & $\$ 791.71$ & 0.071 & $\$ 11,150.83$ & $\$ 31,754 / \mathrm{QALY}$ & + \\
\hline & & $(\mathrm{HP})$ & $\$ 786.13$ & 0.071 & $\$ 11,072.71$ & $\$ 31,754 / \mathrm{QALY}$ & + \\
\hline Hatoum 2014 [59] & US & $\begin{array}{l}\text { BioHA + conven- } \\
\text { tional care vs } \\
\text { conventional care }\end{array}$ & $\$ 1048.13$ & 0.024 & $\$ 43,671.75$ & $\$ 57,529 / \mathrm{QALY}$ & + \\
\hline Bellamy 2016 [36] & US & $\begin{array}{l}\text { Ketorolac vs } \\
\text { corticosteroid } \\
\text { (injection) }\end{array}$ & NR & NR & Dominant & NR & + \\
\hline Rosen 2016 [68] & US & $\begin{array}{l}\text { Euflexxa + con- } \\
\text { ventional care vs } \\
\text { conventional care }\end{array}$ & $\$ 574.82$ & 0.115 & $\$ 4,998.46$ & $\$ 54,663 / \mathrm{QALY}$ & + \\
\hline Rosen 2019 [39] & US & $\begin{array}{l}\text { HMW HA vs } \\
\text { NSAID/analgesic } \\
\text { medication }\end{array}$ & $\$ 273.33$ & 0.026 & $\$ 10,512.77$ & $\$ 51,534 / \mathrm{QALY}$ & + \\
\hline Rosen 2020 [71] & US & $\begin{array}{l}\text { HMW HA vs LMW } \\
\text { HA }\end{array}$ & $\$ 87.61$ & 0.029 & $\$ 3020.96$ & \$51,534/QALY & + \\
\hline $\begin{array}{l}\text { Samuelson } 2020 \\
\text { [72] }\end{array}$ & US & PRP vs HA & $\$ 1477.66$ & 0.11 & $\$ 13,015.63$ & $\$ 51,534 / \mathrm{QALY}$ & + \\
\hline Castro 2015 [65] & Colombia & $\begin{array}{l}\text { Hylan G-F } 20 \text { vs } \\
\text { CST }\end{array}$ & NR & NR & Dominant & NR & + \\
\hline \multicolumn{8}{|l|}{ Opioids } \\
\hline Marshall 2006 [51] & US & $\begin{array}{c}\text { Oxycodone vs } \\
\text { oxycodone }+ \\
\text { paracetamol }\end{array}$ & $\$ 1054.90$ & 0.0105 & $\$ 100,467.71$ & $\begin{array}{l}\$ 68,511-\$ 137,022 / \\
\text { QALY }\end{array}$ & + \\
\hline \multirow[t]{2}{*}{ Smith 2017 [69] } & US & $\begin{array}{l}\text { Tramadol vs opioid- } \\
\text { sparing }\end{array}$ & $\$ 1999.77$ & 0.04 & $\$ 42,765.01$ & $\$ 111,098 / \mathrm{QALY}$ & - \\
\hline & & $\begin{array}{l}\text { Tramadol + oxyco- } \\
\text { done vs opioid- } \\
\text { sparing }\end{array}$ & $\$ 5777.11$ & 0.05 & $\$ 128,028.74$ & $\$ 111,098 / \mathrm{QALY}$ & - \\
\hline
\end{tabular}

$C S T$ conventional supportive therapy, $H A$ hyaluronic acid, $H M W$ high molecular weight, $H P$ health care system perspective, $I A$ intra-articular, $I C E R$ incremental cost-effectiveness ratio, $L M W$ low molecular weight, $N R$ not reported, NSAID non-steroidal anti-inflammatory drug, $O T C$ over-the-counter, $P P I$ proton pump inhibitor, $P R P$ platelet-rich plasma, $Q A L Y$ quality-adjusted life-year, $S P$ social perspective, WOMAC the Western Ontario McMaster University Osteoarthritis Index

Table 6 Cost-effectiveness estimates across continents ( 1 study)

\begin{tabular}{|c|c|c|c|c|c|c|c|}
\hline References & Country/region & $\begin{array}{l}\text { Intervention } \\
\text { and com- } \\
\text { parator }\end{array}$ & $\Delta$ Cost (US\$) & $\begin{array}{l}\Delta \text { Effec- } \\
\text { tiveness } \\
\text { (QALY) }\end{array}$ & ICER (US\$) & $\begin{array}{l}\text { Cost-effective- } \\
\text { ness threshold } \\
\text { (US\$) }\end{array}$ & $\begin{array}{l}\text { Intervention cost } \\
\text { effective? (+/-) }\end{array}$ \\
\hline \multicolumn{8}{|l|}{ SYSADOAs } \\
\hline \multirow[t]{3}{*}{$\begin{array}{c}\text { Bruyère } 2009 \\
\text { [34] }\end{array}$} & $\begin{array}{l}\text { France, Belgium, } \\
\text { Austria, Swit- } \\
\text { zerland, US }\end{array}$ & $\begin{array}{l}\text { Chondroitin } \\
\text { sulfate vs } \\
\text { placebo } \\
(6 \mathrm{mo})\end{array}$ & $\$ 120.45-\$ 193.57$ & 0.011 & $\begin{array}{l}\$ 10930.17- \\
\$ 27799.73\end{array}$ & $\$ 40,085 / \mathrm{QALY}$ & + \\
\hline & & $(12 \mathrm{mo})$ & $\$ 240.91-\$ 387.14$ & 0.011 & $\begin{array}{l}\$ 12688.80- \\
\$ 20392.15\end{array}$ & $\$ 40,085 / \mathrm{QALY}$ & + \\
\hline & & (24 mo) & $\$ 481.81-\$ 774.26$ & 0.011 & $\begin{array}{l}\$ 17299.89- \\
\$ 27799.73\end{array}$ & $\$ 40,085 / \mathrm{QALY}$ & + \\
\hline
\end{tabular}

ICER incremental cost-effectiveness ratio, $Q A L Y$ quality-adjusted life-year, SYSADOAs symptomatic slow-acting drugs for osteoarthritis 
model. Therefore, the importance of selecting an appropriate comparator is becoming increasingly apparent, and the interpretation of cost-effectiveness analysis between active comparators requires some caution [60].

Threshold ICER plays a central role in the methodology and application of CEAs, since the intervention ICERs are compared against the threshold to determine whether new interventions offer good value for money. There are several factors requiring consideration here. (i) There are fundamental differences in the threshold values for cost per QALY between different countries or healthcare systems. (ii) Some studies have specified a threshold range rather than a single value [51, 61]. (iii) In some studies, the threshold value against which the intervention ICERs should be compared is unknown. These factors may support the current view that a single ICER threshold should not be applied in CEAs involving a diverse range of technologies and conditions [85]. Moreover, defining an ICER threshold value might be more appropriate in a national health service system, where healthcare budgets are well-defined and more fixed than in a social security system, where the maximum level of total copayments of the entire population is undefined [85-89]. To ensure efficient healthcare resource allocation, such issues surrounding the definition of ICER thresholds need to be thoroughly considered together with the study population involved.

Our review provides a different perspective on CEA evaluations on the pharmacological management of OA. Although a number of previous reviews have been published on different aspects of this topic [21, 24, 90-94], they have typically described a limited range of therapies and were mostly published more than 5 years ago. Our study provides up-to-date, comprehensive information on a more complete range of OA pharmacological interventions, including oral drugs and IA injections. In addition, in light of limited reviews reporting standardized inflation rates, our study presented pooled economic results that were adjusted by 'purchasing power parity' (PPP) and time period, and normalized across different countries. It is interesting to note that $87 \%$ of the studies included in our review were conducted in Europe and North America, which may suggest an increasing OA burden in these regions, but is also reflective of strong HTA institutions and the use of economics in decision making and market value.

The interpretation of findings presented in our review is subject to a few limitations. First, high-quality studies that were not published in English but otherwise satisfy the inclusion criteria were not considered in our analysis, which may have made our results more relevant for Englishspeaking countries. Second, our investigation was limited to pharmacoeconomic analyses that presented ICERs or found an intervention to be dominant. We are aware of costminimization studies in which certain treatments have been found cost-saving, and which were analogous to the included CEAs, but were not considered in our analysis since ICERs were not calculated [95-100]. Finally, since the included studies span a period of approximately two decades, some of the pharmaceutical prices have dropped significantly since these studies were published, particularly if they were in the 2000s. The findings of these studies therefore may not accurately depict the current market value of the same pharmaceuticals.

\section{Conclusion}

The findings of this systematic review suggest substantial uncertainty regarding the ICER estimates for OA pharmacological therapies, due to the heterogeneity of the included studies. Nevertheless, the results of most studies indicated cost effectiveness of the intervention based on specific ICER thresholds. There are fundamental differences in the threshold values for cost per QALY in studies, which is contributed by the difference in the threshold determination method used. Further efforts are needed to increase the standardization and quality of applied methods, and future studies should report the threshold that was used to determine cost effectiveness.

Supplementary Information The online version contains supplementary material available at https://doi.org/10.1007/s40258-022-00717-0.

\section{Declarations}

Funding Open Access funding enabled and organized by CAUL and its Member Institutions. This study was supported by the National Natural Science Foundation of China (81802204), China Postdoctoral Science Foundation (2020M671453), Natural Science Foundation of Shanxi Province (201801D221117), Program for the Outstanding Innovative Teams of Higher Learning Institutions of Shanxi (2019L0410), and National Health and Medical Research Council (Australia; GNT1120249).

Conflict of interest The authors declare that we have no financial or personal relationships with other people or organizations that could inappropriately influence our work.

Ethics approval Not applicable.

Consent to participate Not applicable.

Consent for publication Not applicable.

Availability of data and material All data generated or analyzed during this study are included in this published article and its supplementary information files.

Code availability Not applicable.

Author contributions All authors contributed to the study conception and design. Material preparation, data collection and analysis were 
performed by JYS, KNF, LY, ZJF, FL, GSW, HMY, JJL, and BW. The first draft of the manuscript was written by JYS, JJL, and BW and all authors provided comment and revision on subsequent versions of the manuscript. All authors read and approved the final manuscript.

Open Access This article is licensed under a Creative Commons Attribution-NonCommercial 4.0 International License, which permits any non-commercial use, sharing, adaptation, distribution and reproduction in any medium or format, as long as you give appropriate credit to the original author(s) and the source, provide a link to the Creative Commons licence, and indicate if changes were made. The images or other third party material in this article are included in the article's Creative Commons licence, unless indicated otherwise in a credit line to the material. If material is not included in the article's Creative Commons licence and your intended use is not permitted by statutory regulation or exceeds the permitted use, you will need to obtain permission directly from the copyright holder. To view a copy of this licence, visit http://creativecommons.org/licenses/by-nc/4.0/.

\section{References}

1. Global, regional, and national incidence, prevalence, and years lived with disability for 354 diseases and injuries for 195 countries and territories, 1990-2017: a systematic analysis for the Global Burden of Disease Study 2017. Lancet. 2018;392(10159):1789-858.

2. Hunter DJ, Schofield D, Callander E. The individual and socioeconomic impact of osteoarthritis. Nat Rev Rheumatol. 2014;10(7):437-41.

3. Prieto-Alhambra D, Judge A, Javaid MK, Cooper C, Diez-Perez A, Arden NK. Incidence and risk factors for clinically diagnosed knee, hip and hand osteoarthritis: Influences of age, gender and osteoarthritis affecting other joints. Ann Rheum Dis. 2014;73(9):1659-64.

4. Turkiewicz A, Petersson IF, Björk J, Hawker G, Dahlberg LE, Lohmander LS, et al. Current and future impact of osteoarthritis on health care: a population-based study with projections to year 2032. Osteoarthritis Cartilage. 2014;22(11):1826-32.

5. Global, regional, and national incidence, prevalence, and years lived with disability for 310 diseases and injuries, 1990-2015: a systematic analysis for the Global Burden of Disease Study 2015. Lancet. 2016;388(10053):1545-602.

6. Vos T, Abajobir AA, Abbafati C, Abbas KM, Abate KH, AbdAllah F, et al. Global, regional, and national incidence, prevalence, and years lived with disability for 328 diseases and injuries for 195 countries, 1990-2016: A systematic analysis for the Global Burden of Disease Study 2016. The Lancet. 2017;390(10100):1211-59.

7. Woolf AD, Pfleger B. Burden of major musculoskeletal conditions. Bull World Health Organ. 2003;81(9):646-56.

8. Xing D, Xu Y, Liu Q, Ke Y, Wang B, Li Z, et al. Osteoarthritis and all-cause mortality in worldwide populations: grading the evidence from a meta-analysis. Sci Rep. 2016;18(6):24393.

9. Gupta S, Hawker GA, Laporte A, Croxford R, Coyte PC. The economic burden of disabling hip and knee osteoarthritis (OA) from the perspective of individuals living with this condition. Rheumatology (Oxford). 2005;44(12):1531-7.

10. Calders P, Van Ginckel A. Presence of comorbidities and prognosis of clinical symptoms in knee and/or hip osteoarthritis: A systematic review and meta-analysis. Semin Arthritis Rheum. 2018;47(6):805-13.
11. Hsu PS, Lin HH, Li CR, Chung WS. Increased risk of stroke in patients with osteoarthritis: a population-based cohort study. Osteoarthritis Cartilage. 2017;25(7):1026-31.

12. Mould-Quevedo J, Luna-Casas G, Garcia-Mollinedo L, RosadoBuzzo A. Adverse events costs associated with pain management in adult patients with osteoarthritis and rheumatoid arthritis in five latin american countries. Value Health. 2013;16(3):A221.

13. Cutolo M, Berenbaum F, Hochberg M, Punzi L, Reginster JY. Commentary on recent therapeutic guidelines for osteoarthritis. Semin Arthritis Rheum. 2015;44(6):611-7.

14. Zhang W, Moskowitz RW, Nuki G, Abramson S, Altman RD, Arden N, et al. OARSI recommendations for the management of hip and knee osteoarthritis, Part II: OARSI evidencebased, expert consensus guidelines. Osteoarthritis Cartilage. 2008;16(2):137-62.

15. Bannuru RR, Osani MC, Vaysbrot EE, Arden NK, Bennell K, Bierma-Zeinstra SMA, et al. OARSI guidelines for the non-surgical management of knee, hip, and polyarticular osteoarthritis. Osteoarthritis and cartilage. 2019;27(11):1578-89.

16. Gammie T, Vogler S, Babar ZU. Economic evaluation of hospital and community pharmacy services. Ann Pharmacother. 2017;51(1):54-65.

17. Hiligsmann M, Cooper C, Arden N, Boers M, Branco JC, Luisa Brandi M, et al. Health economics in the field of osteoarthritis: an Expert's consensus paper from the European Society for Clinical and Economic Aspects of Osteoporosis and Osteoarthritis (ESCEO). Semin Arthritis Rheum. 2013;43(3):303-13.

18. Peinemann F, Labeit A. Varying results of early benefit assessment of newly approved pharmaceutical drugs in Germany from 2011 to 2017: A study based on federal joint committee data. J Evid Based Med. 2019;12(1):9-15.

19. Kamaruzaman H, Kinghorn P, Oppong R. Cost-effectiveness of surgical interventions for the management of osteoarthritis: a systematic review of the literature. BMC Musculoskelet Disord. 2017;18(1):183.

20. Pinto D, Robertson MC, Hansen P, Abbott JH. Cost-effectiveness of nonpharmacologic, nonsurgical interventions for hip and/or knee osteoarthritis: Systematic review. Value Health. 2012;15(1):1-12.

21. Xie F, Tanvejsilp P, Campbell K, Gaebel K. Cost-effectiveness of pharmaceutical management for osteoarthritis pain: a systematic review of the literature and recommendations for future economic evaluation. Drugs Aging. 2013;30(5):277-84.

22. Woods B, Manca A, Weatherly H, Saramago P, Sideris E, Giannopoulou C, et al. Cost-effectiveness of adjunct non-pharmacological interventions for osteoarthritis of the knee. PLoS ONE. 2017;12(3): e0172749.

23. Shahabi S, Rezapour A, Arabloo J. Economic evaluations of physical rehabilitation interventions in older adults with hip and/or knee osteoarthritis: a systematic review. Eur J Physiother. 2019;2:2.

24. Wielage RC, Myers JA, Klein RW, Happich M. Cost-effectiveness analyses of osteoarthritis oral therapies: a systematic review. Appl Health Econ Health Policy. 2013;11(6):593-618.

25. Decimoni TC, Leandro R, Rozman LM, Craig D, Iglesias CP, Novaes HMD, et al. Systematic review of health economic evaluation studies developed in Brazil from 1980 to 2013. Front Public Health. 2018;6:52.

26. Moher D, Shamseer L, Clarke M, Ghersi D, Liberati A, Petticrew $\mathrm{M}$, et al. Preferred reporting items for systematic review and meta-analysis protocols (PRISMA-P) 2015 statement. Syst Rev. 2015;4(1):1.

27. van Mastrigt GA, Hiligsmann M, Arts JJ, Broos PH, Kleijnen J, Evers SM, et al. How to prepare a systematic review of economic evaluations for informing evidence-based healthcare decisions: 
a five-step approach (part 1/3). Expert Rev Pharmacoecon Outcomes Res. 2016;16(6):689-704.

28. Ma LL, Wang YY, Yang ZH, Huang D, Weng H, Zeng XT. Methodological quality (risk of bias) assessment tools for primary and secondary medical studies: what are they and which is better? Mil Med Res. 2020;7(1):7

29. Gomersall JS, Jadotte YT, Xue Y, Lockwood S, Riddle D, Preda A. Conducting systematic reviews of economic evaluations. Int J Evid Based Healthc. 2015;13(3):170-8.

30. Jordan JM, Helmick CG, Renner JB, Luta G, Dragomir AD, Woodard J, et al. Prevalence of knee symptoms and radiographic and symptomatic knee osteoarthritis in African Americans and Caucasians: The Johnston County Osteoarthritis Project. J Rheumatol. 2007;34(1):172-80.

31. Ofman JJ, Sullivan SD, Neumann PJ, Chiou CF, Henning JM, Wade SW, et al. Examining the value and quality of health economic analyses: implications of utilizing the QHES. J Manag Care Pharm. 2003;9(1):53-61.

32. Chiou CF, Hay JW, Wallace JF, Bloom BS, Neumann PJ, Sullivan SD, et al. Development and validation of a grading system for the quality of cost-effectiveness studies. Med Care. 2003;41(1):32-44.

33. Gerkens S, Crott R, Cleemput I, Thissen JP, Closon MC, Horsmans $\mathrm{Y}$, et al. Comparison of three instruments assessing the quality of economic evaluations: a practical exercise on economic evaluations of the surgical treatment of obesity. Int $\mathbf{J}$ Technol Assess Health Care. 2008;24(3):318-25.

34. Bruyère $\mathrm{O}$, Scholtissen $\mathrm{S}$, Neuprez $\mathrm{A}$, Hiligsmann $\mathrm{M}$, Toukouki A, Reginster JY. Impact of chondroitin sulphate on health utility in patients with knee osteoarthritis: Towards economic analysis. J Med Econ. 2009; 12(4):356-60.

35. Chou CW, Lue KH, Lee HS, Lin RC, Lu KH. Hylan G-F 20 has better pain relief and cost-effectiveness than sodium hyaluronate in treating early osteoarthritic knees in Taiwan. J Formos Med Assoc. 2009;108(8):663-72.

36. Bellamy JL, Goff BJ, Sayeed SA. Economic impact of ketorolac vs corticosteroid intra-articular knee injections for osteoarthritis: A randomized, double-blind Prospective Study. J Arthroplasty. 2016;31(9):293-7.

37. Contreras-Hernandez I, Mould-Quevedo JF, Torres-Gonzalez R, Goycochea-Robles MV, Pacheco-Dominguez RL, Sanchez-Garcia $\mathrm{S}$, et al. Cost-effectiveness analysis for joint pain treatment in patients with osteoarthritis treated at the Instituto Mexicano del Seguro Social (IMSS): Comparison of nonsteroidal antiinflammatory drugs (NSAIDs) vs cyclooxygenase-2 selective inhibitors. Cost Eff Resour Alloc. 2008;6:21.

38. Migliore A, Integlia D, Pompilio G, Di Giuseppe F, Aru C, Brown T. Cost-effectiveness and budget impact analysis of viscosupplementation with hylan G-F 20 for knee and hip osteoarthritis. ClinicoEcon. 2019;11:453-64.

39. Rosen J, Niazi F, Dysart S. Cost-Effectiveness of Treating Early to Moderate Stage Knee Osteoarthritis with Intra-articular Hyaluronic Acid Compared to Conservative Interventions. Adv Ther. 2019;2:2.

40. Haglund U, Svarvar P. The Swedish ACCES model: predicting the health economic impact of celecoxib in patients with osteoarthritis or rheumatoid arthritis. Rheumatology (Oxford). 2000;39(Suppl 2):51-6.

41. Svarvar P, Aly A. Use of the ACCES model to predict the health economic impact of celecoxib in patients with osteoarthritis or rheumatoid arthritis in Norway. Rheumatology (Oxford). 2000;39(Suppl 2):43-50.

42. Kamath CC, Kremers HM, Vanness DJ, O'Fallon WM, Cabanela RL, Gabriel SE. The cost-effectiveness of acetaminophen, NSAIDs, and selective COX-2 inhibitors in the treatment of symptomatic knee osteoarthritis. Value Health. 2003;6(2):144-57.

43. Moore A, Phillips C, Hunsche E, Pellissier J, Crespi S. Economic evaluation of etoricoxib versus non-selective NSAIDs in the treatment of osteoarthritis and rheumatoid arthritis patients in the UK. Pharmacoeconomics. 2004;22(10):643-60.

44. Yen ZS, Lai MS, Wang CT, Chen LS, Chen SC, Chen WJ, et al. Cost-effectiveness of treatment strategies for osteoarthritis of the knee in Taiwan. J Rheumatol. 2004;31(9):1797-803.

45. Torrance GW, Raynauld JP, Walker V, Goldsmith CH, Bellamy N, Band PA, et al. A prospective, randomized, pragmatic, health outcomes trial evaluating the incorporation of hylan G-F 20 into the treatment paradigm for patients with knee osteoarthritis (Part 2 of 2): economic results. Osteoarthritis Cartilage. 2002;10(7):518-27.

46. Loyd M, Rublee D, Jacobs P. An economic model of long-term use of celecoxib in patients with osteoarthritis. BMC Gastroenterol. 2007;04(7):25.

47. Ward A, Bozkaya D, Fleischmann J, Dubois D, Sabatowski R, Caro JJ. Modeling the economic and health consequences of managing chronic osteoarthritis pain with opioids in Germany: comparison of extended-release oxycodone and OROS hydromorphone. Curr Med Res Opin. 2007;23(10):2333-45.

48. Bessette L, Risebrough N, Mittmann N, Roussy JP, Ho J, Zlateva G. Cost-utility of celecoxib use in different treatment strategies for osteoarthritis and rheumatoid arthritis from the Quebec healthcare system perspective. J Med Econ. 2009;12(3):246-58.

49. Black C, Clar C, Henderson R, MacEachern C, McNamee P, Quayyum Z, et al. The clinical effectiveness of glucosamine and chondroitin supplements in slowing or arresting progression of osteoarthritis of the knee: a systematic review and economic evaluation. Health Technol Assess. 2009;13(52):1-148.

50. Latimer N, Lord J, Grant RL, O'Mahony R, Dickson J, Conaghan PG, et al. Cost effectiveness of COX 2 selective inhibitors and traditional NSAIDs alone or in combination with a proton pump inhibitor for people with osteoarthritis. BMJ. 2009;339:b2538.

51. Marshall DA, Strauss ME, Pericak D, Buitendyk M, Codding C, Torrance GW. Economic evaluation of controlled-release oxycodone vs oxycodone-acetaminophen for osteoarthritis pain of the hip or knee. Am J Manag Care. 2006;12(4):205-14.

52. Castelnuovo E, Cross P, Mt-Isa S, Spencer A, Underwood M, Team Ts. Cost-effectiveness of advising the use of topical or oral ibuprofen for knee pain; the TOIB study [ISRCTN: 79353052]. Rheumatology (Oxford). 2008;47(7):1077-81.

53. Brereton N, Winn B, Akehurst R. The cost-effectiveness of celecoxib vs diclofenac in the treatment of osteoarthritis in the $\mathrm{UK}$; an update to the NICE model using data from the CONDOR trial. J Med Econ. 2012;15(3):465-72.

54. Wielage R, Bansal M, Wilson K, Klein R, Happich M. Costeffectiveness of duloxetine in chronic low back pain: A Quebec societal perspective. Spine. 2013;38(11):936-46.

55. Wielage RC, Bansal M, Andrews JS, Klein RW, Happich M. Cost-utility analysis of duloxetine in osteoarthritis: A US private payer perspective. Appl Health Econ Health Policy. 2013;11(3):219-36.

56. Wielage RC, Bansal M, Andrews JS, Wohlreich MM, Klein RW, Happich M. The cost-effectiveness of duloxetine in chronic low back pain: A US private payer perspective. Value Health. 2013;16(2):334-44.

57. Brereton N, Pennington B, Ekelund M, Akehurst R. A costeffectiveness analysis of celecoxib compared with diclofenac in the treatment of pain in osteoarthritis (OA) within the Swedish health system using an adaptation of the NICE OA model. J Med Econ. 2014;17(9):677-84.

58. Capel M, Tornero J, Zamorano JL, Oyagüez I, Casado MT, Sánchez-Covisa J, et al. Efficiency of naproxen/esomeprazole in 
association for osteoarthrosis treatment in Spain. Reumatologia Clinica. 2014;10(4):210-7.

59. Hatoum HT, Fierlinger AL, Lin SJ, Altman RD. Cost-effectiveness analysis of intra-Articular injections of a high molecular weight bioengineered hyaluronic acid for the treatment of osteoarthritis knee pain. J Med Econ. 2014;17(5):326-37.

60. Wielage RC, Patel AJ, Bansal M, Lee S, Klein RW, Happich M. Cost effectiveness of duloxetine for osteoarthritis: a Quebec societal perspective. Arthritis Care Res. 2014;66(5):702-8.

61. Scholtissen S, Bruyère O, Neuprez A, Severens JL, HerreroBeaumont G, Rovati L, et al. Glucosamine sulphate in the treatment of knee osteoarthritis: Cost-effectiveness comparison with paracetamol. Int J Clin Pract Suppl. 2010;64(6):756-62.

62. Turajane T, Chaweevanakorn U, Sungkhun P, Larbphiboonpong V, Wongbunnak R. Cost-utility analysis and economic burden of knee osteoarthritis treatment: the analysis from the real clinical practice. J Med Assoc Thailand. 2012;95:S98-104.

63. Thomas T, Amouroux F, Vincent P. Intra articular hyaluronic acid in the management of knee osteoarthritis: Pharmaco-economic study from the perspective of the national health insurance system. PLoS ONE. 2017;12(3):e0173683.

64. Hermans J, Reijman M, Goossens LMA, Verburg H, BiermaZeinstra SMA, Koopmanschap MA. Economic evaluation of chondroitin sulfate and non-steroidal antiinflammatory drugs for the treatment of osteoarthritis Cost-Utility Analysis ofHigh MolecularWeight Hyaluronic Acid for Knee Osteoarthritis in Everyday Clinical Care in Patients at aWorking Age: An Economic Evaluation ofa Randomized Clinical Trial. Arthritis Care Res. 2018;70(1):89-97.

65. Castro JC, Daza AM, Misas JD. Cost-effectiveness analysis of viscosupplementation versus conventional supportive therapy for knee osteoarthritis in Colombia. Value Health Reg Issues. 2015;8:56-61.

66. Nasef SA, Shaaban AA, Mould-Quevedo J, Ismail TA. The costeffectiveness of celecoxib versus non-steroidal anti-inflammatory drugs plus proton-pump inhibitors in the treatment of osteoarthritis in Saudi Arabia. Health Econ Rev. 2015;5(1):53.

67. Katz JN, Smith SR, Collins JE, Solomon DH, Jordan JM, Hunter DJ, et al. Cost-effectiveness of nonsteroidal anti-inflammatory drugs and opioids in the treatment of knee osteoarthritis in older patients with multiple comorbidities. Osteoarthritis and Cartilage. 2016;24(3):409-18.

68. Rosen J, Sancheti P, Fierlinger A, Niazi F, Johal H, Bedi A. Cost-effectiveness of different forms of intra-articular injections for the treatment of osteoarthritis of the knee. Adv Ther. 2016;33(6):998-1011.

69. Smith SR, Katz JN, Collins JE, Solomon DH, Jordan JM, Suter LG, et al. Cost-effectiveness of tramadol and oxycodone in the treatment of knee osteoarthritis. Arthritis Care Res. 2017;69(2):234-42.

70. Losina E, Usiskin IM, Smith SR, Sullivan JK, Smith KC, Hunter DJ, et al. Cost-effectiveness of generic celecoxib in knee osteoarthritis for average-risk patients: a model-based evaluation. Osteoarthritis Cartil. 2018;26(5):641-50.

71. Rosen J, Niazi F, Dysart S. Cost-effectiveness of treating early to moderate stage knee osteoarthritis with intra-articular hyaluronic acid compared to conservative interventions. Adv Ther. 2020;37(1):344-52.

72. Samuelson EM, Ebel JA, Reynolds SB, Arnold RM, Brown DE. The cost-effectiveness of platelet-rich plasma compared with hyaluronic acid injections for the treatment of knee osteoarthritis. Arthroscopy. 2020;36(12):3072-8.

73. Chirikov VV, Walker C, Stephens JM, Schepman P, Chambers $\mathrm{R}$, Bakir M, et al. Evaluating the cost-effectiveness of celecoxib versus ibuprofen and naproxen in patients with osteoarthritis in united arab emirates based on the precision trial. ClinicoEcon Outcomes Res. 2021;13:409-20.

74. Karasawa Y, Kamae I, Nozawa K, Zeniya S, Murata T, Soen $\mathrm{S}$, et al. Cost-effectiveness analysis of branded and authorized generic celecoxib for patients with chronic pain in Japan. PLoS ONE. 2021;16:7.

75. Sullivan JK, Huizinga J, Edwards RR, Hunter DJ, Neogi T, Yelin E, et al. Cost-effectiveness of duloxetine for knee OA subjects: the role of pain severity. Osteoarthr Cartil. 2021;29(1):28-38.

76. Sun X, Zhen X, Hu X, Li Y, Gu SY, Gu Y, et al. Cost-utility analysis of imrecoxib compared with diclofenac for patients with osteoarthritis. Cost Effect Resour Alloc. 2021;19:1.

77. Bellamy N, Buchanan WW, Goldsmith CH, Campbell J, Stitt LW. Validation study of WOMAC: a health status instrument for measuring clinically important patient relevant outcomes to antirheumatic drug therapy in patients with osteoarthritis of the hip or knee. J Rheumatol. 1988;15(12):1833-40.

78. Safiri S, Kolahi AA, Smith E, Hill C, Bettampadi D, Mansournia MA, et al. Global, regional and national burden of osteoarthritis 1990-2017: a systematic analysis of the Global Burden of Disease Study 2017. Ann Rheum Dis. 2020;79(6):819-28.

79. Gore M, Tai KS, Sadosky A, Leslie D, Stacey BR. Clinical comorbidities, treatment patterns, and direct medical costs of patients with osteoarthritis in usual care: a retrospective claims database analysis. J Med Econ. 2011;14(4):497-507.

80. Hunter DJ, Bierma-Zeinstra S. Osteoarthritis. Lancet. 2019;393(10182):1745-59.

81. Shields GE, Buck D, Elvidge J, Hayhurst KP, Davies LM. Costeffectiveness evaluations of psychological therapies for schizophrenia and bipolar disorder: a systematic review. Int J Technol Assess Health Care. 2019;35(4):317-26.

82. Arden NK, Perry TA, Bannuru RR, Bruyère $\mathrm{O}$, Cooper C, Haugen IK, et al. Non-surgical management of knee osteoarthritis: comparison of ESCEO and OARSI 2019 guidelines. Nat Rev Rheumatol. 2021;17(1):59-66.

83. Shields GE, Elvidge J. Challenges in synthesising cost-effectiveness estimates. Syst Rev. 2020;9(1):289.

84. Luhnen M, Prediger B, Neugebauer EAM, Mathes T. Systematic reviews of health economic evaluations: a structured analysis of characteristics and methods applied. Res Synth Methods. 2019;10(2):195-206.

85. Cleemput I, Neyt M, Thiry N, De Laet C, Leys M. Using threshold values for cost per quality-adjusted life-year gained in healthcare decisions. Int $\mathbf{J}$ Technol Assess Health Care. 2011;27(1):71-6.

86. Rawlins MD, Culyer AJ. National institute for clinical excellence and its value judgments. BMJ. 2004;329(7459):224-7.

87. Gafni A, Birch S. Incremental cost-effectiveness ratios (ICERs): the silence of the lambda. Soc Sci Med. 2006;62(9):2091-100.

88. Shiroiwa T, Igarashi A, Fukuda T, Ikeda S. WTP for a QALY and health states: More money for severer health states? Cost Eff Resour Alloc. 2013;11:22.

89. Bruyère $\mathrm{O}$, Cooper C, Al-Daghri NM, Dennison EM, Rizzoli R, Reginster JY. Inappropriate claims from non-equivalent medications in osteoarthritis: a position paper endorsed by the European Society for Clinical and Economic Aspects of Osteoporosis, Osteoarthritis and Musculoskeletal Diseases (ESCEO). Aging Clin Exp Res. 2018;30(2):111-7.

90. van Dieten HE, Korthals-de Bos IB, van Tulder MW, Lems WF, Dijkmans BA, Boers M. Systematic review of the cost effectiveness of prophylactic treatments in the prevention of gastropathy in patients with rheumatoid arthritis or osteoarthritis taking non-steroidal anti-inflammatory drugs. Ann Rheum Dis. 2000;59(10):753-9.

91. Brown TJ, Hooper L, Elliott RA, Payne K, Webb R, Roberts C, et al. A comparison of the cost-effectiveness of five strategies for 
the prevention of non-steroidal anti-inflammatory drug-induced gastrointestinal toxicity: A systematic review with economic modelling. Health Technol Assess. 2006;10(38):iii-183.

92. Chen YF, Jobanputra P, Barton P, Bryan S, Fry-Smith A, Harris $\mathrm{G}$, et al. Cyclooxygenase-2 selective non-steroidal anti-inflammatory drugs (etodolac, meloxicam, celecoxib, rofecoxib, etoricoxib, valdecoxib and lumiracoxib) for osteoarthritis and rheumatoid arthritis: a systematic review and economic evaluation. Health Technol Assess. 2008;12(11):1-278.

93. Huelin R, Pokora T, Foster TS, Mould JF. Economic outcomes for celecoxib: a systematic review of pharmacoeconomic studies. Expert Rev Pharmacoecon Outcomes Res. 2012;12(4):505-23.

94. Salmon JH, Rat AC, Charlot-Lambrecht I, Eschard JP, Jolly D, Fautrel B. Cost effectiveness of intra-articular hyaluronic acid and disease-modifying drugs in knee osteoarthritis. Pharmacoeconomics. 2018;36(11):1321-31.

95. Lizán Tudela L, Magaz Marqués S, Varela Moreno C, Riesgo BY. Analysis of cost-minimisation treatment with paracetamol or
COX-2 inhibitors (rofecoxib) for pain from arthrosis of the knee or hip. Aten Primaria. 2004;34(10):534-40.

96. McKell D, Stewart A. A cost-minimisation analysis comparing topical versus systemic NSAIDs in the treatment of mild osteoarthritis of the superficial joints. Br J Med Econ. 1994;7:137-46.

97. Soto J. Economic evaluation of diclofenac/misoprostol versus rofecoxib in the treatment of arthrosis. Atencion Farmac. 2001;3(1):30-7.

98. Tarricone R, Martelli E, Parazzini F, Darbà J, Le Pen C, Rovira $\mathrm{J}$. Economic evaluation of nimesulide versus diclofenac in the treatment of osteoarthritis in France Italy and Spain. Clin Drug Invest. 2001;21(7):453-64.

99. Vargas E, Laredo L, Soto J, Rejas J. Economic evaluation of celecoxib in the treatment of arthrosis. Atencion Farmac. 2002;4(2):72-82.

100. Vidal J, Benito P, Manresa A, Ly-Pen D, Batlle E, Blanco FJ, et al. Economic evaluation of tramadol/paracetamol in the management of pain in patients with osteoarthritis in Spain. Reumatol. 2011;7(4):241-7.

\title{
Authors and Affiliations
}

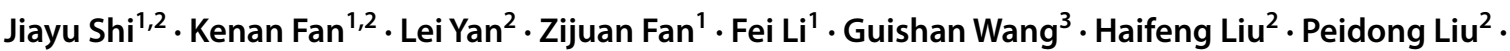 \\ Hongmei $\mathrm{Yu}^{1} \cdot$ Jiao Jiao $\mathrm{Li}^{4} \cdot$ Bin Wang ${ }^{2,5}$
}

1 Department of Health Statistics, School of Public Health, Shanxi Medical University, Taiyuan, China

2 Department of Orthopaedic Surgery, Shanxi Medical University Second Affiliated Hospital, Taiyuan, China

3 Department of Biochemistry and Molecular Biology, Shanxi Medical University, Taiyuan, China
$4 \quad$ School of Biomedical Engineering, Faculty of Engineering and IT, University of Technology Sydney, Ultimo, NSW 2007, Australia

5 Department of Orthopaedic Surgery, The First Affiliated Hospital, Zhejiang University School of Medicine, Hangzhou, China 